\title{
¿Culto heroíco durante la primera edad del Hierro e Ibérico anti- guo en el noreste peninsular? Algunas consideraciones a partir del registro funerario.
}

\author{
Raimon Graells i Fabregat
}

\section{Resumen}

En este trabajose consideran diversas evidencias funerarias singulares del noreste peninsular fechables entre los ss. VII y $\mathrm{V}$ aC. Los paralelos en la Península y especialmente en el Mediterráneo permiten relacionar estos contextos con prácticas de carácter circunmediterráneo.

Palabras clave: Culto heroico, Culto a los ancestros, tumba, cipo, Cataluña.

\section{Summary:}

In this work I consider some singular funerary evidences in the northeast of the lberian peninsula, between the 7th and 5th centuries b.C. The parallels in the Peninsula and especially in Mediterranean allow us to relate these contexts with characteristic Mediterranean practices.

Key Words: Hero cult, ancestor's, tomb, Cippus, Catalonia.

La variabilità a livello regionale, quando non addirittura locale, che caratterizza il rituale funerario, e in generale la cultura materiale della Prima Età del Ferro, mal si concilia con una visione unitaria della storia sociale in questa complessa fase di transizione. Esistono tuttavia elementi del rituale funerario che, al di là dei particolarismi locali, si prestano ad una lettura che superi il limitato orizzonte della singola comunità. (Marini 2003: 21-22).

\section{INTRODUCCIÓN}

Las manifestaciones del poder, el significado de los objetos y especialmente las gestas de los grandes hombres han centrado la curiosidad de todo tipo de eruditos, historiadores y arqueólogos a lo largo del tiempo. La fascinación que desde los inicios de los estudios de protohistoria despertaron las tumbas de guerreros y las leyendas (principalmente las homéricas), permitió que este imaginario de mitos, guerreros

1 Departament d'Història, secció d'Arqueologia, Prehistòria i Història Antiga, Universitat de Lleida, Pl.Víctor Siurana, 1, y héroes se pudiera identificar en el registro arqueológico. Con el tiempo, esta misma pasión, ha ido marcando unas directrices hasta formalizar lo que se ha llamado "arqueología heroica", que ha funcionado como una subdisciplina híbrida entre la arqueología clásica y la protohistoria mediterránea. $\mathrm{El}$ interés por estos temas ha derivado a menudo en aspectos de la emergencia aristocrática o de la afirmación de la misma, fenómenos que han ayudado a reunir un mayor número de estudiosos. La atención que ha recibido esta disciplina no ha decaído con el paso de los años, a pesar de su intermitencia, que no permite concretar un momento de eclosión de estos estudios. Son excelentes ejemplos de esta actualidad, las exposiciones recientemente celebradas bajo los títulos de L'Europe au temps d'Ulysse, dieux et heros de l'Âge du Bronze (Copenhagen, Bonn, Paris y Atenas, 19982000) y Guerrieri, Principi ed Eroi, fra il Danubio e il Po dalla Preistoria all'Alto Medioevo (Trento 2004) pero también destacan debates y mesas redon-

25003, Lleida. raimongf@historia.udl.cat 
das como la reunión organizada por el departamento de arqueología clásica e historia antigua de la Universidad de Gotteborg bajo el título de Ancient Greek Hero Cult (1995) o las publicaciones de An Archaeology of Ancestors: Greek Tomb and Hero Cult de C.Antonaccio (1995) y Pindar and the Cult of Heroes de B.Currie (2005)2. La investigación de la Península Ibérica, normalmente, no ha entrado en estas tendencias interpretativas de carácter circunmediterráneo, hecho que no impide que pueda aplicar-se en toda su magnitud para algunos casos particulares. Afortunadamente, diversos contextos (el monumento de Porcuna o el santuario de El Pajarillo entre otros) y materiales (conjunto iconográfico de las matrices de la tumba del orfebre de Cabezo Lucero, etc.) han normalizado el uso del término "héroe" y "heroico". Pero esta realidad, o mejor aún, esta posibilidad de observar cultos heroicos o comportamientos de índole mediterránea se han circunscrito únicamente al sur de la Península Ibérica. Si bien es cierto que la reali- dad material y cultural del mundo ibérico que ocupó el sur peninsular difiere en gran medida del que ocupó el extremo noreste ${ }^{4}$, en este trabajo nos preguntamos sobre la existencia, o no, de los elementos básicos para poder hablar de culto heroico durante la protohistoria en estos territorios septentrionales. Por eso es necesario tratar la confrontación entre los conceptos de culto heroico de carácter mediterráneo y las evidencias que se documentan en los contextos protohistóricos catalanes. Para evaluar esta dimensión cultual he elegido una visión desde el registro funerario, centrada en el s.VI AC, donde la evaluación del grado de madurez de la sociedad, de los restos materiales y del conocimiento de este imaginario serán los elementos que permitirán proponer una serie de conclusiones sobre esta cuestión ${ }^{5}$. Pero la voluntad del trabajo, va más allá, intentando organizar el desciframiento y el desarrollo de la emergencia aristocrática entre el Ebro y el Empordà.

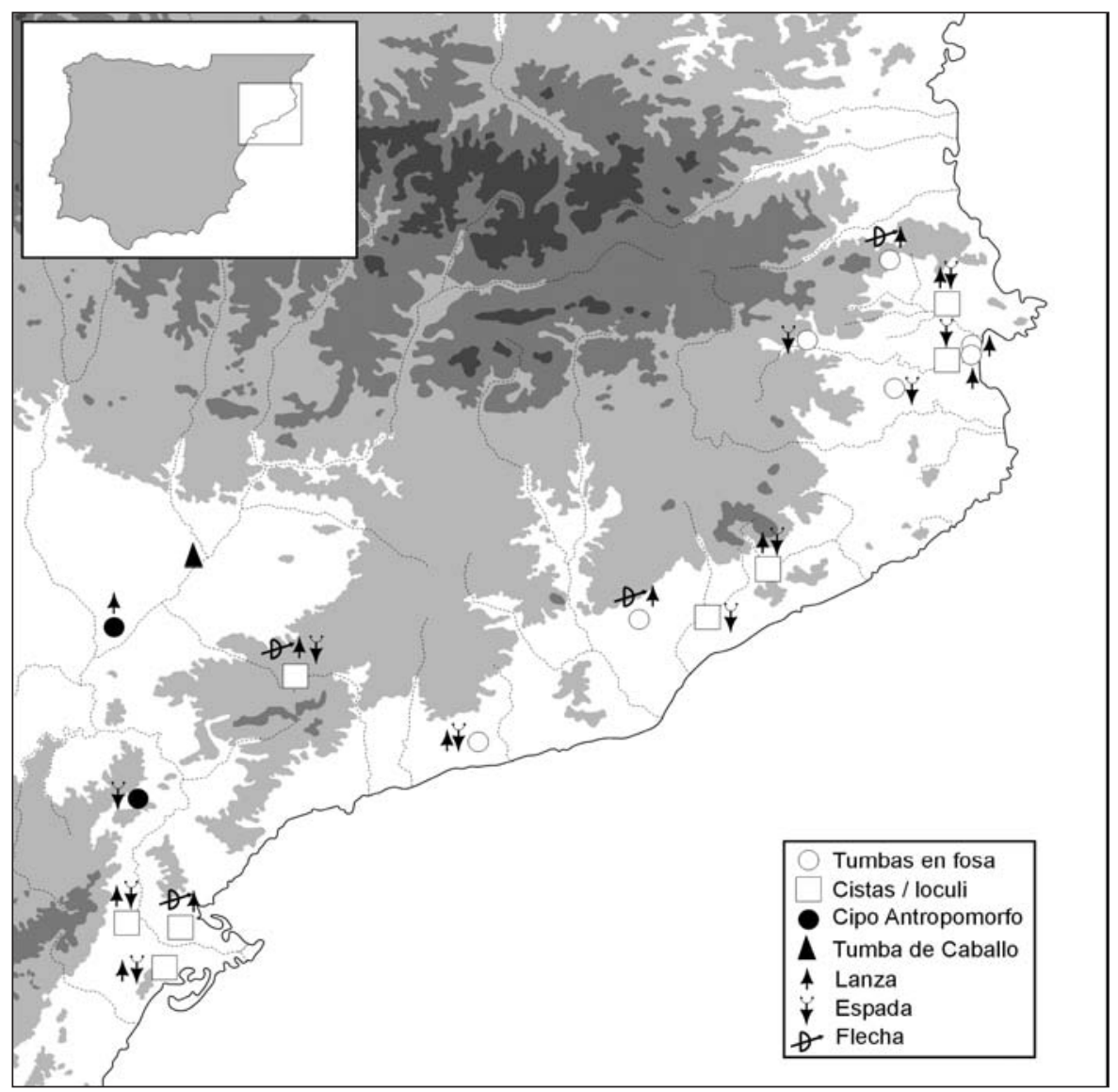

Fig 1.- Mapa de Cataluña con indicación de los hallazgos analizados y referidos en el texto.

2 Intentar recoger toda la bibliografía existente sobre el tema es prácticamente imposible debido a la cantidad y diferentes enfoques desde los que se ha tratado el problema.

3 Quesada 1994; Sanmartí 2007; Uroz 2006; etc.

4 Aunque J.Sanmartí ha demostrado ciertas analogías a nivel de organización social (2004) y cultural (2007)
5 De este modo, dejo de lado las evidencias que podrían sugerir tanto las escasas representaciones escultóricas y las representaciones de las estelas de tipo "Bajo Aragón" aparecidas en Cataluña y sus alrededores, que permiten un interesante debate sobre la "heroización" (Quesada 1994; Sanmartí 2007: 243). 


\section{LAS DIMENSIONES DEL HÉROE.}

Definir al héroe y los estadios de su culto se convierte en la primera necesidad para plantearse la existencia o no de culto heroico. Cabe recordar la advertencia de M.T. Guaitoli (2004: 17) sobre la dificultad de distinguir al héroe del príncipe o del guerrero, dadas las similitudes en la forma de representarse $^{6}$. Para hallar estos personajes, es necesaria la existencia de una profunda estratificación social, que por consenso, debe estar dirigida por una elite político-militar que en muchos casos combinará también un carácter sacro. En esta línea, ha sido a menudo propuesta la relación entre héroes y control del territorio, como sistema de legitimación para la explotación del mismo. A pesar de la propuesta de A.Snodgrass, donde se propone la explotación agrícola (Snodgrass 1982: 117; Chaume, Olivier, Reinhard 2000: 324), debe considerarse la posibilidad de un control comercial.

El héroe es tal en base a tres momentos fundamentales, para los que se mantendrá viva su memoria o se inventará el mito (Snodgrass 1982: 107), donde se reconocerá la areté y la timé del mismo7:

- La fundación del grupo: el momento en que se consolida un grupo como unidad clientelar alrededor de un personaje se convierte en el punto de partida para que exista un héroe. La formación de una unidad diferenciada del resto da una identidad al grupo que se diferencia del resto. El fundador da un pasado común, digno de recuerdo y venera-

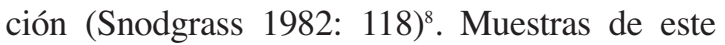
estadio aparecen en la literatura, pero también en el registro arqueológico con los llamados heroa. La tumba del héroe, se sitúa en los niveles fundacionales de la ciudad o núcleo del grupo heredero de su figura, como lugar de culto. Ejemplos clásicos de estos fundadores son los de Erechteus y Akademos, el primero en el punto actualmente ocupado por el templo de Niké en la Acrópolis, el segundo en cambio a poca distancia del Gimnasio (Coldstream 1976: 16). Muy posiblemente, estas tumbas, sean en la mayoría de caso ficticias, ceno-

6 Vid. Infra.

7 Otras propuestas, se concentran únicamente en el momento final del personaje. Así la propuesta de Svembro (1976), recogida también por Valenza-Mele (1991: 159, nota 37), se resume en tres estadios: el funeral y el ajuar; la tumba; y el epos (gestas del personaje). Mazarakis (1999:10), también considera tres momentos: el culto a la tumba, el culto al personaje heroizado y culto al personaje epónimo. Pero considero que estos estadios o momentos se organizan de forma equívoca y olvidan el momento fundamental para que alguien dé culto a otro personaje. Creo que es imprescindi- tafios, situándose las tumbas reales de los diferentes personajes en la leyenda o en un punto más singular del territorio, como límite o punto de control del mismo. Otras veces, la sepultura de personajes dentro de hábitats debe ser interpretado como una falta de distinción entre espacio habitacional y sepulcral (Bartoloni 2003: 105) ${ }^{9}$.

- Las gestas durante la vida: La leyenda, memoria colectiva del grupo, se recrea en aquellas gestas que han enriquecido el imaginario de la comunidad. El recuerdo se convierte en muestra de orgullo del conjunto y en motivo de veneración. Arqueológicamente, se recuperan esas gestas a partir de la representación del héroe. Así los casos de los monumentos de Porcuna (Cerrillo Blanco, Jaén), con las escenas de la vida desde la infancia hasta la muerte, o el monumento funerario de Pozomoro con escenas mitológicas, o el monumento de el Pajarillo (Huelma, Jaén), con la representación de la conquista del territorio inhóspito, se convierten en representaciones que reflejan la leyenda y se convierten por lo tanto en lugares de culto.

- La muerte: es el momento de máxima cohesión del grupo. La construcción de la tumba, monumental en la mayoría de casos, implica la elección del lugar en el territorio. Este punto se convierte en símbolo del héroe, quien guía su vida y su muerte desligado de vínculos de dependencia hacia su comunidad. La unión con el territorio se manifiesta de dos maneras: como hito de su posesión en vida, y desde su muerte posesión del grupo; y como punto de protección, desde donde el difunto vigila. Estas dos posiciones, convierten estas tumbas en lugares de culto. A pesar de la dificultad de documentar restos de ofrendas en el exterior de las mismas tumbas.

Estos tres momentos, permiten reconocer al héroe, pero en Cataluña y en el noreste peninsular en general, tenemos de reconstruir los diferentes estadios a partir de la cultura material, mayoritariamente concentrada en el último momento de los estadios

ble unir en un mismo momento el funeral, el ajuar y la tumba, así como los tres tipos de culto en uno de único.

8 «...Les savants ont souvent suligné comment les poèmes homériques et hésiodiques attestent. En ordre de nombreux passages, que les familles aristocratiques du temps de l'énonciation se réclamaient de la descendance des héros et donc, en dernier lieu, de quelque divinité» (Tosetti 2006 : 116).

9 Aunque para la primera edad del hierro en Cataluña, estas áreas se presentan bien diferenciadas. 
presentados. Otra suerte tuvieron los personajes de los relatos homéricos, disponiendo de memoria, primero oral y luego escrita, de sus gestas y distintas evidencias arqueológicas que permiten reconocer efectos de su culto y de su muerte ${ }^{10}$. A estas conjeturas se debe advertir del riesgo que se corre de hallarnos ante otras realidades dentro de los registros funerarios. Estas pueden corresponder principalmente a distintas formas de expresión del poder. Así el caso de las tumbas 184, 192 y 399 de la necrópolis ampurdanesa de Agullana, o la tumba 8 de la necrópolis de Anglès podrían ser excelentes ejemplos. todas sin armas, pero con una riqueza muy superior al resto de tumbas de sus respectivas necrópolis. Hasta el caso de la tumba 184 de Agullana, se debe considerar como propia de un personaje extranjero introducido en la comunidad de Agullana a partir de su status (Graells 2004), hecho que distorsiona la lectura normal de la necrópolis. Este mismo fenómeno, la introducción de personajes de rango elevado en otras comunidades se repite por toda Europa durante la protohistoria, distorsionando tanto las relaciones de riqueza de los ajuares como las organizaciones de la necrópolis y los tipos de tumbas, entre otros cambios en el ritual funerario ${ }^{11}$. De esta manera se interpreta con frecuencia la transmisión de estos elementos a partir del intercambio matrimonial principalmente llevado a cabo por mujeres $^{12}$.

Otro problema viene asociado a la afirmación de Guaitoli (2004: 17), donde la distinción entre el héroe y el príncipe es en muchos casos un problema de difícil solución. Tal es así que el diferente grado de riqueza pueda provocar errores en la determinación de lo que es un personaje heroizado y lo que es únicamente un personaje de elevado estatus social. El análisis debe realizarse valorando los distintos aspectos que hemos anunciado y el contexto donde se ubica el conjunto. Así las tumbas 61 y 65 de la necrópolis de el Molar (Priorat), la 257 de Roques de Sant Formatge (Seròs, Segrià) o la 207 de Agullana (Alt Empordà), no pueden ser consideradas en ningún casos como tumbas heroicas, a pesar

10 Menelaion; Agamemnoneion; etc.

${ }^{11}$ Véase por ejemplo los casos de la tumba 600 d'Osteria del'Osa (Lacio, Italia) con una rica panoplia militar en bronce (Bietti Sestieri 1992), la tumba de Wiesbaden-Erbenheim con extraña joyería y posición fetal (Pauli 1977); la tumba 1 de la necrópolis de Salamina, que según Gjerstad corresponde a una aristócrata ática casada con un miembro de la familia real de Salamina (Gjerstad 1979: 89-93); otros ejemplos han sido interpretados a partir de la difusión de algunos tipos de materiales, especialmente las fíbulas, entre las que desta- de la extraordinaria riqueza de sus ajuares metálicos. Lo mismo pasa con las tumbas M1 del Coll del Moro (Gandesa, Terra Alta) y con la tumba 2 de la Colomina (Gerb, La Noguera), donde las dimensiones, muy superiores al resto, tampoco serían motivos suficientes para ser consideradas tumbas de héroes.

Por lo tanto las tumbas "excepcionales" deben ser estudiadas con un cuidado especial, debido a la enorme importancia de las variaciones en el ritual funerario. Este frágil equilibrio, en romperse confiere al respectivo conjunto una clara voluntad de diferenciarse del resto de la comunidad donde se documenta (Graells 2004: 63), y por lo tanto una relación especial con los estatus y roles significantes.

\section{Armas y Caballos}

Siguiendo con la advertencia de Guaitoli también algunos atributos pueden llevar a confundir el héroe con el príncipe-guerrero o el gran guerrero, especialmente ciertas armas y los caballos.

En Cataluña, durante la protohistoria, es usual la presencia de tumbas con armas, que se pueden clasificar en base a una gradación de carácter local. Así nos encontramos con la necesidad de reconocer una gradación social dentro de la que se debe establecer otra en función del tipo de armas y otra más en función de la riqueza. Siendo los personajes de mayor nivel social y armamento, los que se situarán en el vértice de la pirámide social, en calidad de ostentación del rol político-militar. Es aquí donde se deben reconocer unas características particulares para identificar al personaje como héroe. Algunas interpretaciones recientes, absolutamente aptas para los contextos protohistóricos catalanes, consideran la presencia de armas en tumbas de personajes no adultos masculinos, como símbolos de pertinencia a grupos privilegiados. Los personajes armados, proponen un imaginario que subraya el rango elevado del difunto, su condición aristocrática y por encima de todo la distancia que lo separa de la clase clientelar y siervos (Bartoloni y Delpino

can los estudios sobre les fíbulas itálicas y sus distribuciones hacia centroeuropa (Adam 1992), hacia Cerdeña (Bartoloni 2003: 116) o hacia ámbito griego (Coldstream 1993), pero también otros objetos de joyería o "quincallería" entre comunidades vecinas, como el caso de la necrópolis de Münsingen-Rain (Ruiz-Zapatero y Chapa 1991: 359), etc.

12 Sobre el valor de la mujer como bien intercambiable véase Bartoloni 2003, 1989; Rallo 1989; Vernant 1973; en contra de esta interpretación véase Hodos 1999. 
2000: 226) ${ }^{13}$. Parece imprescindible de cara a valorar el significado de cada tipo de arma, conocer el valor que poseía. El concepto de valor no se debe regir en función de un factor económico sino también simbólico y jerárquico. Las armas que hallamos en las tumbas de las necrópolis catalanas, permiten estructurar a los portadores de armas en una serie de categorías. La combinación de los diferentes tipos, propone una estructura militar piramidal. En esta estructura la espada se convierte en el símbolo de poder y riqueza en cualquier comunidad donde el carácter militar de la elite es predominante (Quesada 1997:162). Así la espada se convierte en una prerrogativa de pocos (Bartoloni y Delpino 2000: 225), tan significativa a nivel de manifestación de poder económico como la coraza o el casco $^{15}$. Por estos motivos podría considerase el símbolo identificador del héroe (Guaitoli 2004:26), pero se caería en el error de obviar el contexto particular en que se documenta. Es innegable pero, que la espada se debe relacionar con la más alta elite social ${ }^{14}$, y que en muchos casos corresponderá al guerrero heroizado. Por lo tanto el imaginario que recrean los personajes armados, pone en relieve el rango elevado del difunto, su condición aristocrática, y subraya por encima de todo la distancia que le separa de las clases inferiores (Bartoloni y Delpino 2000). La tradición admite que las armas como identificadores de los guerreros, sus propietarios, no podían ser adquiridas sino merecidas (Bouvier 2002: 542 y ss.; Marini 2003: 25), y su uso debería quedar restringido al del poseedor (Sopeña 1987) ${ }^{16}$. Como ya señaló F. Quesada, la presencia de espadas es mayoritaria en contextos funerarios, siendo excepcional su hallazgo en hábitats (Quesada 1997: 162) así como en santuarios, donde se documentan algunas miniaturizadas (Graells 2007; Lillo Carpio 1986-1987). Fácilmente esta propuesta esté en relación a la mayor perennidad de los contextos funerarios delante de la renovación y constante movimiento, pragmático, de los objetos en hábitats y santuarios.

Las armas aparecen depositadas en la tumba siguiendo unos patrones concretos que en algunos casos se repiten de forma normal. Es frecuente su aparición alterada por acción del fuego, indicio inne-

13 Por otro lado, no se puede excluir la idea de ofrendas conyugales o de la comunidad en favor del rol desarrollado por el personaje en vida. Mujeres en calidad de sacerdotisas, madres o esposas de personajes singulares dentro de las diferentes comunidades, recibirían un trato especial en el momento de su funeral, distinguiéndose con algunos símbolos del poder fáctico. Lo mismo sucedería con algunos niños, que serían distinguidos en virtud de su ascendencia (familia) o del destino que les esperaba (líder de la comunidad, sacerdote...). Más extraña sería una atribución como elementos identifiacadores del poder desarrollado. gable de que acompañaron al difunto en la pira funeraria; dobladas (Quesada 1997; Farnié y Quesada 2005); sin corte, después de haber sido golpeadas contra algún objeto (según Quesada -1989 y 1997: 162- con una gran piedra); con la hoja perforada o con la hoja fracturada. Todas ellas, evidencias de una voluntad de inutilizar el objeto, también llamada

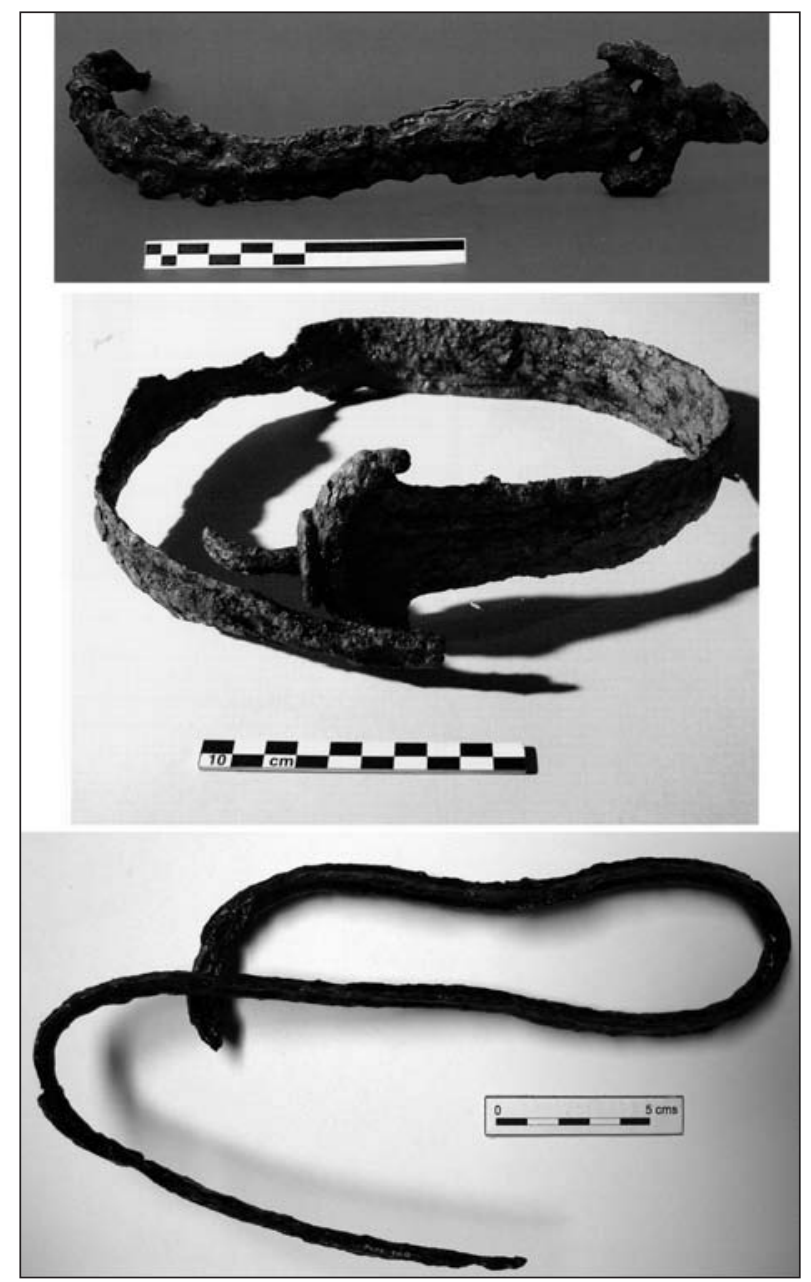

Fig 2.- Espadas inutilizadas (de arriba a bajo): Espada de Can Canyís (Banyeres del Penedès, Tarragona) (Farnié i Quesada 2005, 84-90, ffgg. 5760), Espada de Camallera (Girona) (Farnié $i$ Quesada 2005, 74-77,ffgg. 44-47), Espada de Milmanda (Foto Autor).

14 La espada miniaturizada, según M.Torelli (1997: 21-22; contra Bietti-Sesteri 2000: 232-235), distinguiría el armamento típico de los "seniores", detentores de la "patria potestas" de la familia, respecto a los "juniores" dotados exclusivamente de lanza o "giavelotto", en algunos casos se asociaría también la presencia de escudos miniaturizados, como en Quadrato o en la misma 137 dell'Osteria dell'Osa.

15 En contra véase Quesada 1997: 163.

16 Sobre esta idea volveré inmediatamente. 
"uccisione dell'arma" (Marini 2003: 30). La finalidad de estas inutilizaciones, ha sido interpretada como ritual más que práctica, evidencia de la íntima y personal relación entre el difunto y sus armas, las cuales deben "morir" del mismo modo que el propietario y acompañarlo en la otra vida (Quesada 1997: 162 y 641). Por contra, las opiniones que creen en una actividad práctica consideran el hecho de la colocación de las piezas dentro de los loculi y evitar así una ampliación (Fernández 1986: 797; García Cano 1994: 4323), pero también el hecho de evitar robos o reutilizaciones (Coldstream 1977: 31; Faro, Cañada i Unzu 2002-2003: 53; Quesada 1997: 643; Sopeña 1987). Como observó F. Quesada (1997: 642), en muchos casos la inutilización de las piezas no era necesaria para depositarlas en las tumbas, suficientemente espaciosas. En general, de todos los sistemas de inutilización de armamento, es el doblamiento, el más usual, a pesar de la complejidad tecnológica que implicaba su consecución (calentamiento y martilleado del metal), si se contrapone a la simplicidad de otros sistemas. Espadas, puntas de lanza y sobretodo soliferra fueron las armas mayoritariamente inutilizadas por doblamiento. Normalmente, para los solife$r r a$, ha sido aceptado el doblamiento por motivos prácticos de deposición en el loculus. El distinto tipo de inutilización, conlleva procedimientos tecnológicos diferentes, que se pueden graduar en función de su complejidad, que creemos que no es aleatoria. La técnica del doblado, ha sido documentada de forma mayoritaria en las espadas de la Cataluña protohistórica $^{17}$, mientras que no se documentan las inutilizaciones de las hojas, ni las fracturas intencionales de las hojas. Queda clara la importancia que recibe la inutilización de la espada, comportando un complejo proceso que se inicia con el calentamiento de la hoja; siguiendo con el martilleado para doblar la hoja. Este proceso de calentamiento y martilleado se puede repetir varias veces hasta conseguir el doblado total; finalizando con la deposición en la tumba. Conocidos los distintos casos de inutilización, especialmente espadas, aunque también lanzas y soliferra, son frecuentes en las fuentes clásicas citas a robos de armas en campos de batalla (Il. 17, 188-197; Il. 23, 798-

17 Pla de la Gibrella (Capsech) (Farnié y Quesada 2005, 62-64, ffgg. 30 y 31; Pons 1984; Quesada 1997, 194; Ruíz-Zapatero 1985); Peralada (Farnié y Quesada 2005, 64-68, ffgg. 32-34, 68-69, ffgg. 35-38, 70, ffgg. 39-41, 72m ffgg. 42-43; Pons 1984; Pons y Vila 1977; Quesada 1997, 194-196; RuízZapatero 1985, 895); Camallera (Farnié y Quesada 2005, 74-77, ffgg. 44-47; Pons 1984; Quesada 1997, 194; RuízZapatero 1985, 895); Tomba del Guerrer de la necròpolis del Coll de Llinars del Vallès (Farnié y Quesada 2005, 80-82, ffgg. 52-54, 83-84, ffgg. 55 y 56; Quesada 1997, 197-199;
800), para después ser ofrecidas como dones o como ofrendas (En el caso de las armas de Sarpedonte, como premio en unos juegos funerarios). Su transmisión como objetos de prestigio (Lillios 1999), fue también uno de los sistemas de pervivencia de las armas, como los casos del arco de Odiseo, anteriormente propiedad de Ífito quién lo intercambió por una lanza y una espada (Od. 21, 11-14 i 31-35), la coraza de Agamenón, dada por el rey de Chipre (Il. 11, 19-20) o aún mejor el casco de Aquiles, dado por Anfidamente a Molo, quién lo dejó en herencia a su hijo Merión para acabar en la cabeza de Aquiles (Il.10, 269). Como se observa, algunas de estas donaciones, podían corresponder también a herencias familiares, ejemplificadas en los casos del arco de Ífito recibido de su padre Eurito (Od.21, 31-33) o las armas de Aquiles, herencia de Peleo (Il. 17, 193-197). En referencia a la deposición de armas en tumbas, únicamente conocemos el caso de Elpenor (Od. 11, 74-76) y el de Eezión (Il. 6, 414-420). El motivo de la introducción de armas en los ajuares es distinto en cada caso. En el primero, el deseo de ser recordado como guerrero, en el segundo, por haber muerto en el campo de batalla (y no haber sido despojado de sus armas por Aquiles). Pero se ha puesto en relieve la relación de estos dos casos con el hecho de que ninguno tenía descendencia a quién dejar las panoplias en herencia (Marini 2003: nota 35). Existe la posibilidad de que las armas en tumbas, puedan corresponder en algunos casos a personajes emparentados con los propietarios originales de las armas (Cerdeño y García-Huerta -1990: 91- en base a Silio Itálico -Pun, III, 341-342-).

En algunas regiones, los guerreros muertos en combate no serían enterrados ni incinerados. Quedando pues las armas sin usuarios, pero bajo la responsabilidad de algunos miembros emparentados con el guerreros, apareciendo así la figura del usufructuario, que permite entender casos como el de la tumba de la dama de Baza. El reducido número y el simbolismo de las armas en general, permite interpretarlas como elementos indicadores de estatus. Hecho que pone en relación el esfuerzo económico y la dificultad para adquirirlas. De modo que difícilmente se

Sanmartí 1993, 30); T1 de la necròpolis de Can Canyís (Bea 1996; Farnié y Quesada 2005, 84-90, ffgg. 57-60, 90-92, ffgg. 61-63 Quesada 1997, 196; Ruíz-Zapatero 1985; Vilaseca, Soler y Mañé 1963); Mianes (Farnié y Quesada 2005, 92-96, ffgg.64-67, 96-99, ffgg. 68-73; Maluquer 1987, 132; Oliver 1981, 230; Quesada 1997, 196); Sept. 23 y 27 de la necròpolis de la Solivella (Farnié y Quesada 2005, 99103, ffgg. 74-77, 103-105, ffgg. 78-80; Fletcher 1965; Oliver 1981; Quesada 1997, 199); Milmanda (Graells ep.c). 
amortizarían si aún fueran útiles. De este modo, es más difícil entender la voluntad de inutilizar las armas que van a depositarse en las tumbas. Y se confunde el valor intrínseco de las armas con el de la memoria del guerrero. Muy posiblemente, en algunos casos la destinación de una arma dependerá de su estado, así una arma desfasada o maltrecha, muy posiblemente se inutilizaría y se revalorizaría como objeto simbólico del personaje al que había correspondido. En cambio, armas en buen estado de conservación, se entregarían como dones de prestigio o se dejarían en herencia. De esta manera, se puede entender la presencia de armas en algunas tumbas de mujeres o niños, donde estarían principalmente por el carácter simbólico y no como indicadores del rol social o de la actividad desarrollada. Se puede afirmar pues que la valoración de las armas en el momento de su amortización era principalmente de carácter económico a pesar de mostrar una relación directa con el estatus, pudiendo aceptar que las armas no dejan de tener valor sino que lo transforman: de un valor económico a un valor simbólico.

Por otro lado el caballo, el cual está presente en contextos funerarios catalanes, pero como intentaré demostrar no parece que se fechen en el horizonte que aquí planteamos. La presencia de caballos en contextos protohistóricos ha sido repetidamente señalada como elementos nobles que distinguen a una elite, no recibiendo de esta manera una lectura como animales de tiro o de consumo ${ }^{18}$. En esta línea debe mencionarse el trato singular que recibieron numerosos fetos de caballo en la Fortaleza dels Vilars de Arbeca (Lleida), yacimiento muy cercano a la única necrópolis que presenta sepulturas de caballo: la necrópolis de la Pedrera (Vallfogona de Balaguer), donde eran enterrados dentro del poblado y en situaciones similares a la de los fetos humanos.

En Cataluña, como ya he avanzado, únicamente conocemos los caballos enterrados de la necrópolis

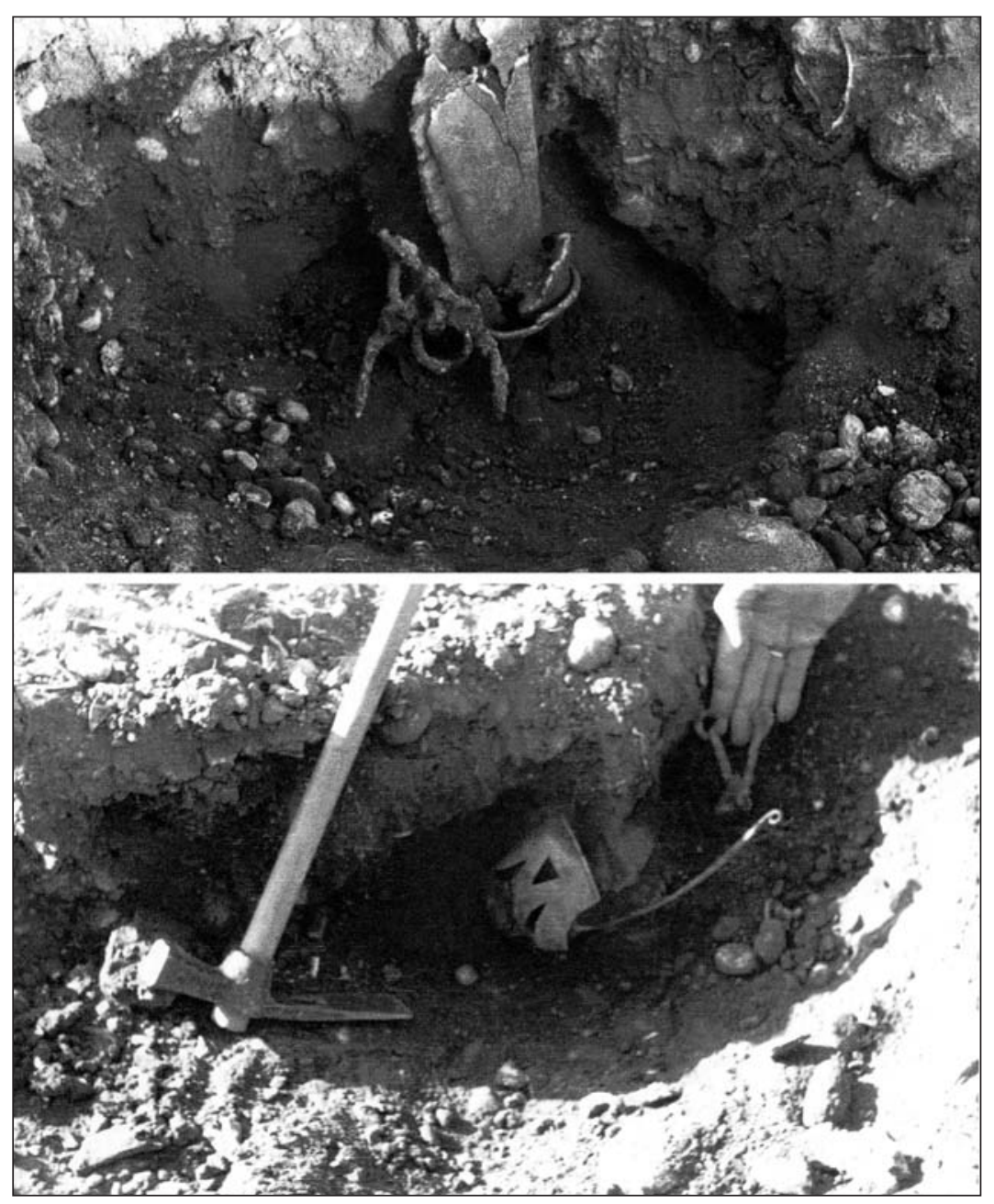

Fig 3.- Hallazgo de dos sepulturas de caballo de la necrópolis de la Pedrera (Vallfogona de Balaguer, Lleida) (Plens y Rafel 2002: Fig.24 y 25).
18 La deposición de caballos delante de tumbas encuentra casos singulares como el de la tumba de Cimón, a la que se asociaron los caballos que le dieron las tres victorias olímpi- cas y que después de muerto el propietario fueron sacrificados (Hr, VI, 103). 
de la Pedrera. Según M.Plens y N.Rafel (2002: 256) debemos considerar que se trata de tres caballos y no de 2 como con seguridad presentan la fotografías del descubrimiento (Plens y Rafel 2002: Fig.24 y 25) o un mínimo de cuatro como podría plantearse a partir de la presencia de cuatro frenos de caballo (Garcès 2002: 200). Los caballos de la Pedrera presentan un problema importante que es la manera en como se recuperaron y excavaron. La recuperación y fotografía de los escasos elementos dificultan una valoración objetiva de los hallazgos. La descripción de una de estas tumbas por M. Plens y N. Rafel (2002: 256), y observa una inhumación de caballo relacionada con una urna de incineración. Por otro lado, la ausencia en la descripción de toda mención a frenos de hierro o bozal de bronce dan a entender que las otras dos inhumaciones son las que se conocen a partir de las fotografías 24 y 25 de las mismas investigadoras. De manera que la segunda inhumación corresponde a, al menos, un cráneo acompañado por un freno de hierro (Plens y Rafel 2002: 255, Fig.24; Plens 1986: Fig.75 o Fig.76). Finalmente, la tercera inhumación presenta restos de un cráneo cubierto por un bozal de bronce y presenta también un freno de hierro (Plens y
Rafel 2002: 256, Fig.25; Plens 1986: Fig.75 o Fig.76). Esta tercera tumba ha sido fechado por E.Junyent entre finales de s.VII e inicios de s.VI AC (Junyent 2003: 96), a pesar que la datación ha sido puesta en duda a partir de la misma tipología del bozal, la cual parece posterior (La Genière 1997).

Este tipo de tumbas, como es bien sabido encuentran pocos i elitistas paralelos ${ }^{19}$, que demuestran que el caballo es una prerrogativa de elevado estatus social, pero que no puede ser puesta directamente en la órbita militar. Sea como sea, inhumar un caballo dentro del complejo de la necrópolis otorga al animal una posición social. Es interesante considerar el porqué de la inhumación completa del caballo en la mayoría de tumbas que conocemos, hecho que contrasta con los restos cárnicos de ofertas votivas ${ }^{20}$.

Lejos de cualquier tipo de ofertas alimenticias se sitúan los sepulcros de caballos (Méniel 2002: 11). La deposición de caballos enteros implica una relación íntima entre el propietario y su caballo y al mismo tiempo una voluntad pública de la sepultura. Esto provoca a la comunidad la realización de un importante número de variaciones en el ritual funerario: $\mathrm{La}$

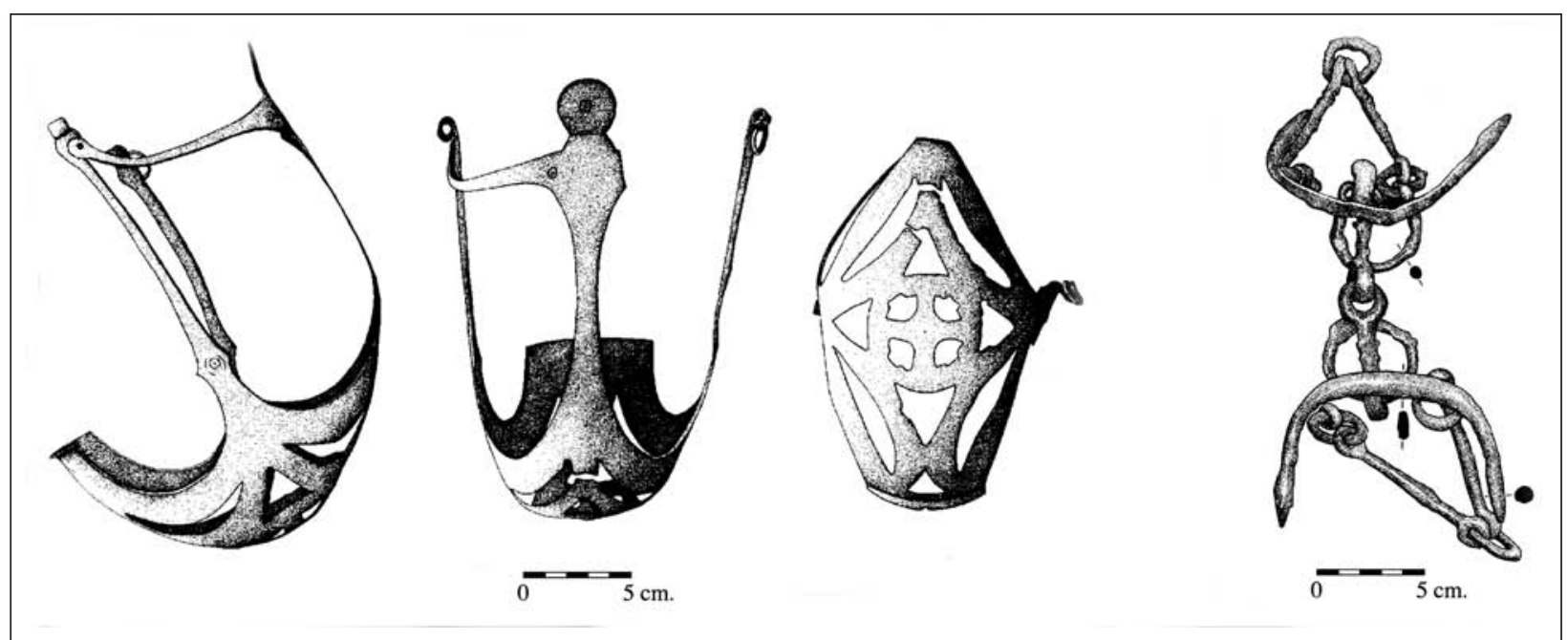

Fig 4.- Bozal de bronce y freno de hierro asociados a los caballos de la necrópolis de la Pedrera (Vallfogona de Balaguer, Lleida) (Garcés 2002a: 198; Garcés 2002b: 200).

19 Inhumación de la Regenta (Mesado y Sarrión 2000: 96, fig.1 y 9); la inhumación 437 de la necrópolis de Olynthus (Robinson 1942: 90); la inhumación del Túmulo 1 de Fau (Cazals, Tarn-et-Garone) (Pajot 1972: 431); la inhumación de la T.68 de Grand Bassin I; la fosa adyacente a la T.II de l'Acciaierie di Terni (Leonelli 2003: 54-55); la tumba de Maccarese (Manfredini 1994: 293); la t.11 de Bologna Benacci-Caprara; la t.7 de Bologna La Mercanzia; la t.19 de Bologna Arnoaldi; la EE109B de Veio Quattro Fontanili; la inhumación humana y de caballo de la tumba ufc13/1989 Piovego-Padova (Leonardi 1990 y 2004); la inhumación de una mujer y un caballo en la tumba de Colombara di Gazzo
Veronese (Salzani 2001); la inhumación de una joven adolescente junto a un caballo de la tumba-silo 201 de Wettolsheim (Haut-Rhin) (Méniel 2002: 11-12); la doble inhumación humana junto a un caballo de la tumba silo de Nantene-sur-Aisne (Ardenes) (Méniel 2002: 12); y otros ejemplos en la necrópolis de Altino (con 21 caballos enterrados), la de Bologna San Vitale, Bologna Benacci, Bologna Malvasia Tortorelli, Bologna Arsenale Militare, Ischia di Castro (aunque asociados a un carro), etc.

20 Cada uno con su particular simbolismo y funcionalidad hasta el momento de su sacrificio: bóvidos - trabajo y lácteos; ovicápridos - lana y lácteos, etc.). 
excavación de una fosa de dimensiones muy superiores a la media de los loculi realizados para depositar los restos humanos. (En el caso que nos ocupa, las incineraciones de la necrópolis de la Pedrera). Aunque de los sepulcros de los caballos de la Pedrera no se conoce ni la forma ni las dimensiones totales de las fosas, ni tan siquiera se conservan los restos a partir de los que podríamos saber si los animales fueron depositados mutilados, descarnados, en avanzado estado de descomposición (como en los casos de las tumbas-silo de Wettolsheim o Nanteuil-sur-Aisne) o si se cortaron los tendones para así poder depositarlos en un espacio menor, tenemos que suponer que se trata de grandes recortes, que representan al mismo tiempo una mayor implicación social del grupo y una mayor ocupación de la superficie útil del espacio de la necrópolis. Pero es la ornamentación y los elementos para su gobierno los elementos que nos aproximarán a su cronología. Por un lado disponemos de un bozal, de varios frenos de hierro y de un narigón. Como ha sido presentado recientemente el "narigón" consiste en un aro macizo de bronce de sección circular, con un diámetro de la sección de aproximadamente $5 \mathrm{~mm}$., con unos extremos asimétricos, uno con un pivote y una perforación y el otro vacío y con otra perforación coincidente, pensados para cerrarse uno dentro de otro y fijarse mediante un remache (Lucas 2004: 104). Este elemento encuentra escasos paralelos ${ }^{21}$ cuya cronología se sitúa durante el s. IV AC y no antes. El bozal, como hemos visto, mesentonía una cronologia similar.
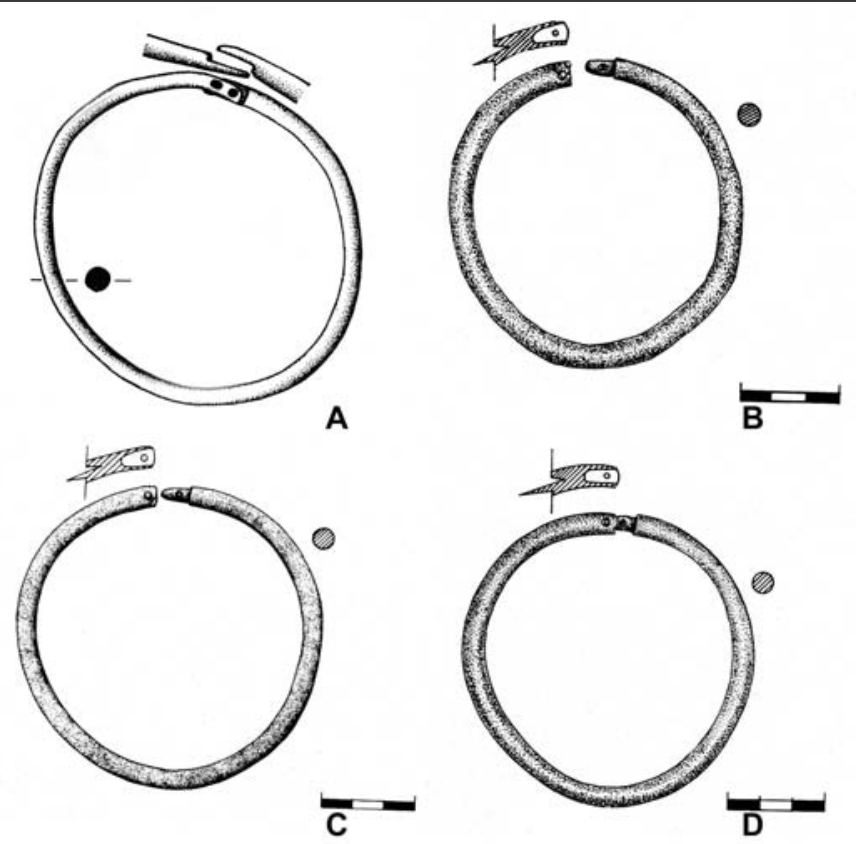

\begin{tabular}{|c|c|c|c|}
\hline Contexto & Diámetro "narigón" & Cronologia & Bibliografia \\
\hline T.200 Cigarralejo & $6 \mathrm{~cm}$ & $400-350 \mathrm{aC}$ & $\begin{array}{l}\text { Cuadrado 1987: 364, Fig.149; Lucas 2004: 104, fig.3.; } \\
\text { Quesada 2002-2003: } 97 ; 2005: 123\end{array}$ \\
\hline Torre d'Onda & $9 \mathrm{~cm}$. & s.l aC & Mesado i Sarrión 2000: 97, fig.10.A \\
\hline Serreta Alcoi & $8,6 \mathrm{~cm}$. & s.IV aC & $\begin{array}{l}\text { Lucas 2004: } 103 \text {, fig.2; Mesado i Sarrión 2000: } 91 \text {, fig. } 4 \\
\text { Quesada 2005: } 123 \text {, fig. } 26\end{array}$ \\
\hline La Regenta & $7,6 \mathrm{~cm}$. & s.IV aC & $\begin{array}{l}\text { Lucas 2004: } 103 \text {; Mesado i Sarrión 2000: } 90 \text {, fig.3; Que- } \\
\text { sada 2005: } 123 \text {, fig. } 27\end{array}$ \\
\hline Puntal dels Llops & $7,6 \mathrm{~cm}$. & s.IV aC & $\begin{array}{l}\text { Lucas 2004: 103; Mesado i Sarrión 2000: 91, fig.5; Que- } \\
\text { sada 2005: } 123\end{array}$ \\
\hline La Pedrera & $8,9 \mathrm{~cm}$ & ¿? & Plens 1985: 112, fig.63.4; Íbidem 2002: 179. \\
\hline
\end{tabular}

Fig 5.- Narigones: A - La Pedrera (Plens 1985: 112, fig.63.4); B - Puntal dels Llops (Mesado y Sarrión 2000: 91, fig.5); C - La Regenta (Mesado y Sarrión 2000: 90, fig.3); D - La Serreta d'Alcoi (Mesado y Sarrión 2000: 91, fig.4). Tabla comparativa de las dimensiones y cronología de Narigones.

21 La Regenta (Lucas 2004: 103; Mesado y Sarrión 2000: 90, fig.3), la Serreta d'Alcoi (Lucas 2004: 103, fig.2; Mesado y Sarrión 2000: 91, fig.4; Quesada 2005: 123, fig.26), OlocauPuntal dels Llops (Lucas 2004: 103; Mesado y Sarrión 2000: 91, fig.5; Quesada 2005: 123), Burriana-Torre d'Onda (Mesado y Sarrión 2000: 96, fig.10.A), Solaig (Mesado y Sarrión 2000: 98) y el de la tumba 200 y del santuario del Cigarralejo (Lucas 2004: 104, fig.3; Quesada 2002-2003:
97; 2005: 123). Posiblemente se pueden asociar otros dos ejemplares, como son los de la Torre d'Onda, con un diámetro de $14 \mathrm{~cm}$. y que Mesado consideró como propio de un bóvido (Mesado y Sarrión 2002: 96-97, fig.10B) y un posible fragmento del extremo hembra, en este caso para un "narigón" de sección cuadrada, procedente del Tossal de les Tenalles de Sidamunt (Plens 2002: 179). 


\section{LA TUMBA AISLADA COMO REFERENTE HEROICO:}

Seguramente, este tipo de tumbas, haya que relacionarlas muy estrechamente con los lugares del culto heroico. El carácter particular de estos sepulcros, conlleva muchas veces la práctica de distintos cultos despues del cierre. En Cataluña, en cambio, no presentan a priori ningún tipo de evidencia de haberlos recibido.

El significado de la tumba aislada se relaciona intrínsecamente con el personaje enterrado. Un personaje digno de ser recordado debe ser enterrado en una tumba digna de ser identificada y por lo tanto recordada. Son sugerentes a tal efecto las palabras de Aquiles cuando quiere ser enterrado junto a Patroclo en la playa del Helesponto, en un túmulo con el fin de poder ser visto desde la distancia (Od., XXIV, 83 y ss.). Esta ubicación elegida por Aquiles no es casualidad.

Parece lógico pensar en la situación de estas tumbas en los lugares de las gestas de los héroes. Su posición se destaca del resto, como sucedió con la figura de su propietario y el resto de su sociedad. Estas tumbas, como ha señalado N.Valena-Mele (1991:159), no se pueden considerar singulares respecto a las comunidades a las que pertenecen, sino comunes entre la vasta clase de héroes. Adaptando la definición que se

22 En las necrópolis de Can Piteu - Can Roqueta, Pla de la Bruguera o el Coll del Llinars del Vallès, las estructuras se presentan mayoritariamente como silos cilíndricos o troncocónicos, que albergan diversos vasos cerámicos. Parece una perduración o reflejo de la periferia de lo que E.Pons ha llamado el fenómeno "mailhacià".

23 Restos de jabalí (Sanmartí et al. 1982: 74) explican la presencia en el ajuar de tres puntas de flecha, símbolos en este caso de la caza como actividad aristocrática.

La presencia de una asta de ciervo sometida al fuego (Campillo 1993:57), encuentra paralelos en la t.136 de Agde (Nickels 1989), y en otras tumbas y contextos es probable su presencia, pero no como piezas en estado bruto, sino formando parte de las cachas de cuchillos o como elementos decorativos de otros objetos.

Distintas son las posibilidades de hallar restos faunísticos en las tumbas protohistóricas. Una propuesta reciente la representa la obra de B.Dedet (2001), pero creo que es preferible diferenciar distintos tipos de ofrendas. Desde ofrendas alimentarias (seleccionando partes específicas para la celebración del banquete y/o para el anfitrión), ofrendas de sacrificios cruentos o no, de carácter meramente religioso (como en algunos casos han sido interpretados los restos de aves y huevos, o en casos donde han aparecido animales enteros) o hasta como partes integrantes de objetos, bien como ornamentos (cuentas de collar, colgantes, etc.) o como útiles (mangos de cuchillos, de espejos, por ejemplo). Lógicamente, cada caso debe valorarse de diferente manera. Sin querer despreciar la presencia de los restos faunísticos en sus condiciones muebles, la hipótesis de trabajo que propongo no trata este tema a pesar de reflexionar sobre la importancia de las ofrendas cárnicas: 1.- Especie representada; 2.- Parte representada (por especie); 3.- Posición dentro realiza de la tumba simple, respecto a las elites que adquieren el poder en las comunidades desde el IIIer milenio AC, se puede aceptar que las tumbas aisladas, generalmente identificadas con personajes heroizados, ostentan esta función en base a una falta de lazos de parentesco, la relación con el territorio y la propiedad de su destino en relación al recuerdo que de ella se tenga (Guilaine y Zammit 2002: 216).

El caso mejor conocido en Cataluña, es el de la Granja de Soley de Sta.Perpètua de la Mogoda (Sanmartí et al. 1982). Teniendo presente el caso de la tumba de Les Ferreres a les Umbries de Calaceit (Cabré 1942) y posiblemente otros hallazgos también en el Bajo Aragón (Rafel 2003). El caso de la tumba de Sta. Perpètua, se trata de una estructura de planta amplia donde se dispone un numeroso ajuar, reproduciendo un tipo de estructura característica de la primera edad del hierro en toda el área del Vallès ${ }^{22}$. Debe destacarse entre el ajuar la presencia de importaciones cerámicas (oenochoe en cerámica gris), vajilla metálica (simpulum y pátera), ornamentos metálicos (broches de cinturón y brazaletes), rica panoplia militar y restos faunísticos ${ }^{23}$, lo que parece menos extraordinario es la abundancia de cerámica de producción local hecha a mano ( 7 piezas) y a torno (4 piezas), hecho que se relacionaría con otras tumbas halladas en necrópolis vecinas ${ }^{24}$. Destaca la presencia de dos

de la tumba; 4.- Relación de la riqueza del ajuar con la especie y la parte representada; 5.- Relación del sexo con la especie y la parte representada; 6.- Relación de la cronología con la especie y la parte representada.

Otro ejemplo de esta exhibición la representan los restos de fauna que se documentan dentro de algunas tumbas y que son indicativas de desechos de banquetes (supuestamente de lujo), como lo demuestran los tipos de animales sacrificados. La selección de las partes en algunas tumbas puede llevarnos a interpretar algún tipo de consumo ritualizado. De este modo no se pueden considerar del mismo modo todas las ofrendas alimenticias, siendo necesario un estudio pormenorizado. Pudiendo distinguir un valor social, económico y simbólico. Así, ciertos animales deben considerarse propios de los círculos aristocráticos, principalmente debemos considerar como tales los animales de caza mayor. Así la importancia del ciervo, se observa en las representaciones de distintos amuletos en bronce de las necrópolis de Coll del Moro de Gandesa, de la Torraza de Valtierra, del Corral de Royo y de la Pedrera de Vallfogona de Balaguer.

24 Como ya ha sido planteado (Graells 2004: 65), éste fenómeno de concentración de numerosos ajuares cerámicos ha sido observado en las necrópolis del sur de Francia. Los arcos relativos al número de elementos cerámicos por tumba en la necrópolis de Recobre II se sitúa entre 5 y 22 vasos (Dedet 1976: 13); en la necrópolis de Grand Bassin I, entre 1 y 58 (Dedet 1976: 13); la necrópolis de Moulin, entre 1 y 7 (Dedet 1976: 13); en la necrópolis de Agde, entre 15 y 25 (Nickels 1981: 104); en la necrópolis de la Cartoule à Servian, entre 5 y 10 (Nickels 1981: 424), con la excepción de la tumba 4, que presenta 24 vasos; en las tumbas 5 y 9 de la necrópolis de Moulin à Vent, el número de piezas es de 29 y 26 vasos respectivamente. 
broches de cinturón de garfios, fenómeno que raramente se documenta; y también la asociación de un set de banquete completo, formado por un simpulum, una pátera y un oenochoe. La tumba pertenecería según D. Campillo ${ }^{25}$, a un joven de entre 17 y 19 años de edad.

\section{LA REPRESENTACIÓN DEL HÉROE:}

Una de les muestras de singularidad es sin lugar a dudas la representación pública del personaje. Como ha argumentado J.Sanmartí "los artefactos cuya realización exigía(n) un mayor grado de elaboración e inversión de energía - y que pueden aparecer a nuestros ojos como obras de arte - debían su singularidad al hecho que desempeñaban funciones ideológicas específicas en el marco de sociedades estratificadas..." (2007: 239), de este modo representaciones figuradas o esquemáticas en escultura y pintura son tan representativas como los símbolos identificadores que se han planteado. Los personajes ilustres deben ser recordados mediante la memoria colectiva (a menudo oral), pero también mediante la memoria visual. Estas muestras, dependiendo del tipo y de su ubicación, tendrían múltiples funciones, desde la delimitación de un territorio a la cohesión del grupo, convirtiéndose en cierta manera en elementos totémicos. Al mismo tiempo, algunas de las muchas formas de representar al personaje, permiten comprender el grado de complejidad social del grupo que las ejecuta. Estos serían los casos de las figurillas de arcilla de algunas de las tumbas de los primeros períodos laciales (Torelli 1993), así como también las miniaturas de armas que se encuentran repartidas por el Mediterráneo $^{26}$. La estructura que muestran este tipo de representaciones recurre al conocimiento colectivo del valor de los símbolos, el uso de los cuales substituye a objetos reales y debido a su carácter miniaturístico se relacionan con el mundo divino (Peroni 2004).

Las representaciones que tenemos en este apartado, corresponden a figuras públicas, destinadas a ser observadas y admiradas. Siendo usadas y destinadas a un momento concreto y predeterminado: el funeral,

25 En el anexo al artículo de Sanmartí et al. 1982.

26 Andronikos 1969: 250-251; Berardinetti y Drago 1997: nota 37; Bietti-Sestieri y De Santis 2003; Bouzek 1997; Canciani 1974: 34; Colonna 1991; Fernández 1992: 174, 272; Gierow 1964; Graells 2007; Kilian 1975: 81; Maluquer 1984: 89; Mancebo 2000; 1983; Bartoloni 2003: 159; Lillo-Carpio 1986-1987; Müller-Karpe 1959; Quesada 1997: 164; Rafel 1993; Ramon 1995; Snodgras 1991: 84 i 94; Sommella 1973-1974.

27 Lo mismo sucederá posteriormente, en época ibero-helenís- en los momentos de la prothesis y en el de la ekpho$r a$. Fijando la memoria en un momento preciso de las gestas, el estatus y el rol del difunto ${ }^{27}$. La representación del héroe, implica su particular pasado, sus gestas, viéndose excluidas todas las representaciones de su vida en el más allá (Valenze-Mele 1991: 158). La representación del héroe implica una inmortalidad terrenal, olvidando lo que pueda suceder una vez muerto.

Debe advertirse que las representaciones de personajes en necrópolis protohistóricas en toda Europa es un fenómeno extraño, el cual se debe considerar con cautela, intentando distinguir dos grandes grupos: los que tienen vocación narrativa (casos del conjunto de Porcuna, Pajarillo...) y los figurativos ${ }^{28}$. En el segundo grupo, se hace distinción entre las figuraciones de personajes divinizados y los personajes psicopompos o apotropáicos.

Como señaló G. Colonna, la representación figurada únicamente se encuentra en tumbas donde el ritual funerario es incineratorio como substitución perenne del cadáver ante su destrucción (Colonna 1986: 37). Cabe recordar la existencia de representaciones figuradas en ámbitos funerarios que no corresponden a personajes heroizados, como serían las urnas volterranas, donde la voluntad reside en prolongar su propia memoria, simulando una heroización. En cambio los vasos canopos etruscos (principalmente de Chiusi) y los ejemplos de las tumbas de Vulci, Albegna (Tomba del Carro dell'Osteria de Vulci: con manos recortadas sobre lámina metálica; Circolo della Fibula de Marsigliana di Albegna: con un busto con cuello y cabeza globular, y brazos tubulares en bronce) y Kleinklein ${ }^{29}$, con representaciones metálicas de partes del cuerpo, corresponden a heroizaciones de personajes enterrados (Iaia 1999: 85-86, notas 10 y 11) como se intuye a partir de la singularidad de las tumbas en que se localizan, junto a la extrema rareza de su hallazgo, cargado de un alto simbolismo.

También son curiosos y significativos los casos de las representaciones que no pertenecen a los personajes enterrados. Así el caso de la tumba delle statue de

tica, con la cerámica con figuras de guerreros y caudillos (Olmos 2002-2003).

28 Algunos ejemplos italianos corresponden a: Manfredonia (Foggia), zona "Beccarini"; Colle Mozzone (tra Atessa e Tornareccio); Guerrero de Capestrano; Casale Maritimo.

29 Kröllkgel, Kleinklein, Gemeinde Grobklein, BH Leibnitz (Stiria, Austria): con una máscara y dos manos recortadas sobre lámina de bronce. Otros ejemplos en Theodossiev 1998. 


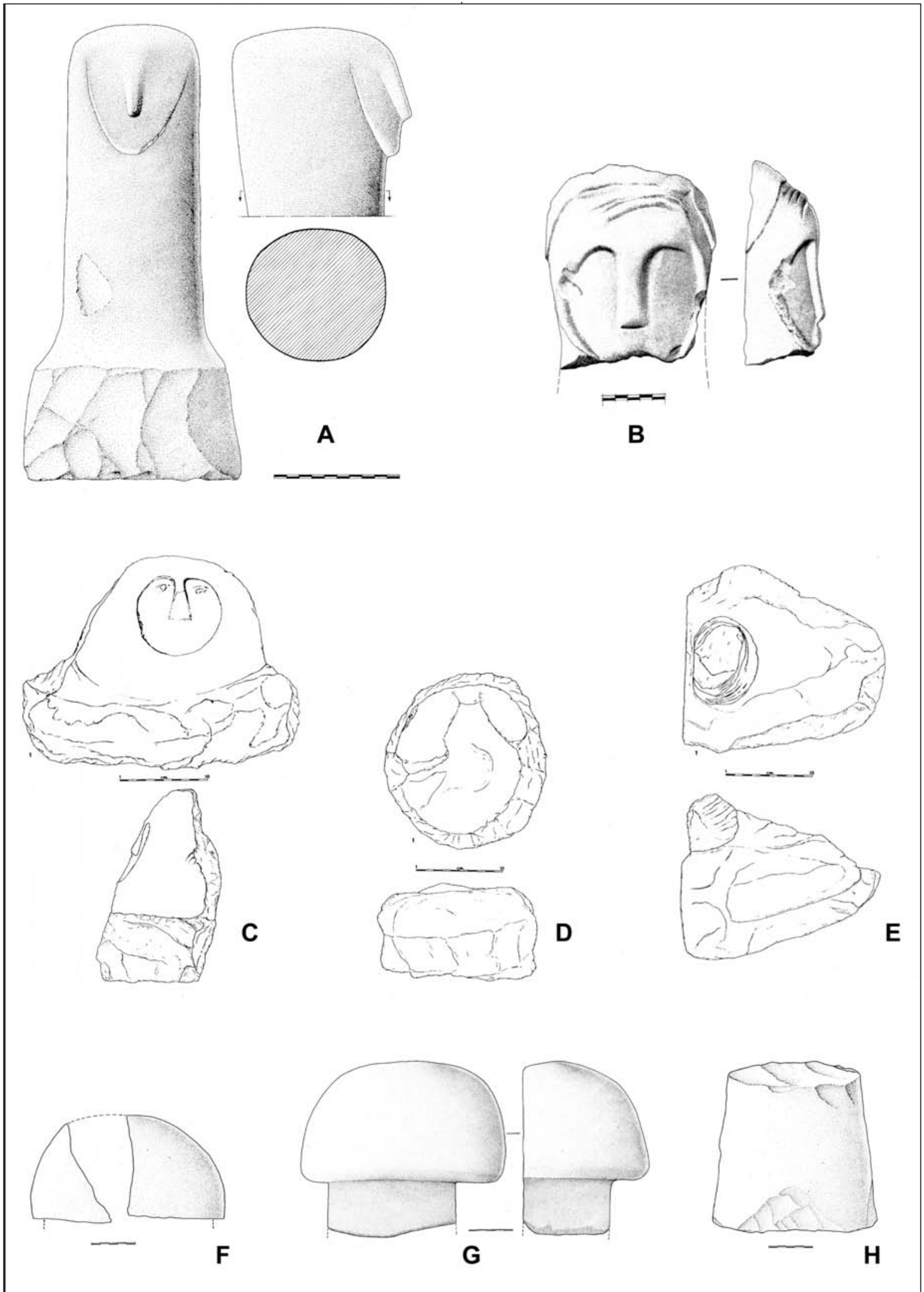

Fig 6.- Estelas con representación antropomorfa y cippi sepulcrales: A - necrópolis de la Pedrera (Vallfogona de Balaguer, Lleida) (Plens 2002: 296). B - Roques de Sant Formatge (Seròs, Lleida) (Colet, Gené y GIP 2005: fig.6); C, D y E-Castellets (Mequinenza, Zaragoza) (Royo 1994: fig. 6, 8 y 9); F, G y H - Coll del Moro (Gandesa, Tarragona) (Rafel 1989: fig.14, 13 y 19). 
Cerveteri, donde se considera que los personajes no son los difuntos de la tumba sino sus antepasados ${ }^{30}$ (Colonna 1986: 38). Pero al mismo tiempo tenemos que suponer algunas otras manifestaciones que no nos han llegado, seguramente debido a la base sobre la que se realizaron. Buen ejemplo de ellas son las supuestas figuras de guerrero de la necrópolis de Desmontà (Lombardía, Italia) identificada por el hallazgo de tres cnémides fuera de cualquier tumba, que teóricamente recubrirían una o varias esculturas situadas entre los sepulcros a modo de indicadores de personajes heroizados ${ }^{32}$. Para ellos, la posición en espacios públicos los identifica como símbolos de la comunidad $^{31}$.

De todos modos, esquematizados o figurativos, podemos aceptar que para el momento que aquí se trata los cippi son una restitución del mnema del difunto (Bruni 2000: 165-167; Steingräber 1991: 1097-1098; Id. 1997: 109-110; Zifferero 2006: 199 , n.29).

Los ejemplos que se documentan en Cataluña, corresponden a los casos de: Roques de Sant Formatge (Seròs, Segrià, Lleida) y de la Pedrera (Vallfogona de Balaguer, La Noguera, Lleida) ${ }^{33}$.

Roques de Sant Formatge: en la campaña de 2002, apareció como parte de la cobertura de un túmulo, una representación antropomorfa sobre piedra arenisca (Colet, Gené y GIP 2005). La figura corresponde a la cara de un personaje de sexo indeterminado (probablemente masculino). Parece clara su correspondencia como representación heroica del difunto (Junyent 2003: 91), a pesar de que existe el dilema de si corresponde a una estela que coronaría el túmulo al que se asocia o si formó parte de alguna otra figura, amortizada como parte del túmulo después de su fractura (aunque parece difícil aceptar la primera opción).

Son conocidos ejemplos de amortización de

\footnotetext{
30 Las dos figuras de la tumba ceretana, representan las imagines maiorum. Lo mismo ha sido propuesto para las figuras de la necrópolis de Casal Maritimo, correspondientes a dos esculturas masculinas que presentan un cinturón del tipo a losagna. Interpretadas como representaciones de ancestros ¿divinizados?, que estaban en la parte superior del túmulo, a modo de indicador o convirtiendo la parte superior del mismo en recinto cultual. Igual que la figura del túmulo de la Pietrera en Vetulonia, que representa una estatua femenina de características y posición hierática, con las manos cruzadas sobre el pecho (posición interpretada en las figurillas de la Tumba Regolini Galassi como posción ritual). Al mismo tiempo que también lleva un cinturón a fascia con la representación de dos grifos en relieve.

31 En muchos casos son los propios datos de excavación los
}

estatuas en las coberturas de tumbas, pero siempre con una clara voluntad de relacionarlas con los difuntos. Así la posición de una representación figurada depositada en el túmulo como en el caso que nos ocupa, con la cara vista, debe ser un acto voluntario que identifica y distingue esta tumba del resto de las de su necrópolis. Esta escultura se relaciona morfológicamente con la encontrada en la vecina necrópolis de Castellets de Mequinensa (Zaragoza), aunque en el segundo caso, ha sido interpretada como cipo.

Cipo antropomorfo de la Pedrera de Vallfogona de Balaguer: Hallado fuera de contexto. Morfológicamente corresponde a un cipo de tipo fálico, con una base cúbica y una parte superior cilíndrica, destinada a señalizar la tumba. Representa una cara esquemática en la parte superior del cilindro. La combinación del tipo de cipo, la escasez de estelas y cippi en Cataluña y algunas de las tumbas documentadas en la necrópolis de la Pedrera permiten identificar esta representación como propia de un personaje masculino heroizado.

Estos elementos enlazan directamente con el culto sobre estas singulares tumbas proponiendo que el significado de que la cobertura del túmulo tuviese una función precisa, de naturaleza sacra y religiosa, viene confirmada por los cippi que sobre ella encontraban su posición/colocación privilegiada, aunque sea extraña la conservación de ellos en su posición original (Colonna 2000: 257).

\section{HeroA y LUGARES DE CULTO:}

Igual que los grandes hombres han suscitado interés y admiración por la investigación, una serie de "muertos anómalos" han representado a lo largo de la historia una vía paralela por la que afrontar el tema del culto heroico. Especialmente el hallazgo de algunas heroa en el interior de centros urbanos (caso

que hacen evidente la presencia de cippi, esculturas, escaleras y altares-terraza, o también varios niveles de superfície del túmulo, pero a menudo con escas posibilidades de reconstruir su posición originaria (Zifferero 2006: 196).

32 El hallazgo se identificó dentro de una fosa sustancialmente separada de la mayoría de tumbas, con las cnémides recubriendo algunos troncos (Salzani 2004: 587).

33 La estela de guerrero proviniente de Ampúrias, publicada por E.Sanmartí el 1988, no puede ser considerada como representación heroica. La interpretación que dá el autor de los motivos representados en la estela como un casco y una lanza/soliferrum inutilizados, no la comparto. Son demasiadas las dudas que supone la interpretación de una espiral como lanza inutilizada, y no soy capaz de identificar el casco entre las línias gravadas sobre la piedra. 
del célebre heroon de Poseidonia) permiten tal relación, la cual está actualmente "de moda" como lo demuestran diversos congresos sobre el tema ${ }^{34}$.

La definición de heroon implica la asociación en un mismo espacio de una tumba y un lugar de culto (Chaume, Olivier y Reinhard 2000: 324). Las tumbas dentro de espacios urbanos y el culto a los ancestros (manifestado con ofrendas sobre tumbas antiguas) se pueden considerar como prácticas de culto heroico. De hecho, el culto heroico en Grecia se ha relacionado con el culto a los ancestros micénicos (Coldstream 1976; Snodgrass 1988), Hasta el punto en que A.Mazarakis (1999:10) considera muy frecuente la confusión entre culto heroico y culto a los ancestros. En este sentido, destaca de manera muy especial una tumba en el área sacra de Sant'Antonio a Cerveteri, que en momentos posteriores se respeta y se recubre con diferentes tipos de piedra, a modo de caja, que ha sido interpretada como una especie de heroon (Bartoloni 2003: 107). Sin duda el conocimiento del pasado y el recuerdo de los hechos acontecidos y de las personas ha sido una constante a lo largo de la historia. Así, durante la antigüedad, el hallazgo de restos se interpretaba en base a un pasado conocido. Bien por el imaginario o mejor aún por el recuerdo. Son abundantes los ejemplos de hallazgos de tumbas durante la antigüedad, que eran interpretadas como propias de héroes o ancestros de las comunidades vecinas. Los numerosos ejemplos los encontramos descritos en las fuentes clásicas. Según los textos clásicos, algunas tumbas de héroes halladas por casualidad fueron: Tumba y monumento funerario de Aliatte (Hdt., II, 93); Tumba de Orestes, descubierta en Tegea y transportados los huesos a Esparta (Hdt., I, 67-68); Tumba de Ajax, descubierta en Salamina con las rótulas de las rodillas como discos de pentatlón (Paus., I, 35, 4-5); Tumba de héroe de la isla de Sciro, con lanza y espada (Plut., Cim.,8; Thes., 36). También encontramos noticias de tumbas heroicas buscadas intencionalmente por los antiguos, como la Tumba de Minos (Diod., IV, 79), la Tumba de Dirce (Plut., De genio Socr., 5, 578b) o la Tumba de Teseo (Plut., Cim., 8).

La importancia de algunas de estas, una vez identificadas como pertenecientes a héroes, con nombre e historia particular, se vé reflejada en los traslados de los restos desde el lugar del descubrimiento a sus ciudades. Los traslados de los restos de Orestes de Tegea a Sparta (Hdt.1.66-68); Tisamenus de Helice a Sparta

34 "Sepolti tra i vivi. Evidenza ed interpretazione di contesti funerari in abitato" celebrado en Roma en abril de 2006 y el segundo encuentro de la série francesa, celebrado el marzo de 2006 en Sens, "Morts anormaux, sépultures bizarres.
(Paus.7.1.8); Alcmena de Tebas a Sparta (Plut., De genio Socr., 5, 577); Minos de Sicilia a Creta (Diod., IV, 79, 3); Teseo de Scyros a Atenas (Plut., Cim., 8); Rhesus de Troya a Amphipolis (Polyaenus Strat. 6.53); Pelops de Eubea a Olimpia (Paus. 5.13.4); Héctor de Troya a Tebas (Lycoph. Alex. 1194-1195, 1204-1205; Paus. 9.18.5); Arcas de Maenalus a Mantinea (Paus. 8.9.3-4); Hippodameia de Midea a Olimpia (Paus. 6.20.7); Orfeo de Libethra a Dión (Paus. 9.30.7); Aristomenes de Rodas a Messene (Paus. 4.32.3); Hesíodo: o de Naupactus a Orchomenos (Paus. 9.31.6; 38.3), o de Ascra a Orchomenos (McCauley 1999: 96, nota 40). Otros ejemplos y noticias de descubrimientos se vieron beneficiados por fenómenos naturales, que llevaron a la superficie restos humanos: el mar abrió la tumba de Ajax (Paus., I, 35, 4-5), un terremoto descubrió un caballo de bronce con una tumba en su interior en Lídia (Phil.Lemn., Heroic., 2, 4), también en Lídia el desmoronamiento de una montaña puso al descubierto restos humanos en Themenothyrai (Paus., I, 35, 78); un alubión desenterró un pithos con restos humanos en Mesenia (Phleg.Trall, FgrHist, 257, F36), etc.

Pero también la casualidad llevó al hallazgo de necrópolis y tumbas, no estrictamente heroicas, o al menos no tratadas así por los autores clásicos. Ejemplificadas en los casos de las tumbas de Delos (Tuc. I, 8, 1) y de Salamina (Plut., Sol., 10, 1; Ael., Var. Hist., VII, 10). Por otro lado, el interés mayoritario por descubrir tumbas y necrópolis fue el saqueo y no el estrictamente religioso, político o histórico. Algunos de los mejores ejemplos son los saqueos de la necrópolis de Corinto (Strab., VIII, 6, 23) y de la necrópolis de Capua (Suet., Caes., 81). Esta práctica no quedó circunscrita en el pasado, sino que desgraciadamente, y ha permanecido hasta el día de hoy.

Dos son los tipos de ofrendas y que se documentan en estas tumbas que han recibido culto o sobre las tumbas identificadas como heroicas:

Les ofrendas en el interior de la tumba, prueba de las cuales sería lo que tradicionalmente se ha llamado "reutilizaciones".

Ofrendas en el exterior de la tumba, muestra del recuerdo del difunto, bien por parte de la comunidad, el grupo al que pertenecía, o a la familia estrecha. La valoración de las mismas ofrendas confieren a la tumba un significado u otro. En Cataluña, se documentan ofrendas sobre pocas tumbas, entre las que

Questions d'interpretation en archeologie funeraire", con el título de la sesión: Les dépôts humains dans les structures d'habitat désaffectées. 
destacan las pertenecientes a la necrópolis del Coll del Moro de Gandesa (Rafel 1991) ${ }^{35}$ y las aún inéditas de Can Piteu-Can Roqueta. Por otro lado se ha hablado de culto a la tumba o a los ancestros, en consideración a la analogía de los materiales a menudo dispuestos sobre la cobertura de numerosas tumbas, normalmente copas rotas, que es importante relacionar con la posible existencia de dos diferentes momentos rituales: uno relacionado con la tumba y el otro a un momento posterior (Vanzetti 1992: 169).

A menudo, los descubrimientos de tumbas eran casuales, y como ha sido bien observado en Grecia, su hallazgo podía conllevar la creación de nuevos cultos. Las fuentes, han dejado también un extenso elenco de estos cultos surgidos a tenor del hallazgo de lo que creían tumbas de héroes fundadores de las distintas comunidades u otros personajes míticos. Otros comportamientos, han sido plenamente conscientes, como símbolos de respeto y veneración, perdurando a lo largo de un determinado período de tiempo. La permanencia en la memoria de la presencia de tumbas, se mezcla rápidamente con el saqueo y el expolio, como hemos visto, más o menos organizado.
Al margen de presentar la posibilidad de un descubrimiento casual de restos antiguos, esta realidad, permite proponer a las comunidades protohistóricas catalanas como propietarias de un complejo imaginario histórico y mitológico. Las distintas evidencias que permiten recordar a un personaje como héroe o una tumba como propiedad de un personaje determinado, ponen en relieve el uso y conocimiento de una estructura ideológica similar a la que presentan griegos, fenicios o etruscos, independientemente del diferente grado de desarrollo cultural. El ejemplo de la t.26 de el Coll del Moro de GandesaSector Teulers (Ferrer 1989), representa el mejor ejemplo de una tumba construida expresamente para recibir culto. El loculus se rodea de 8 piedras trabajadas formando una estructura cuadrangular. Estas piedras presentan un pequeño hoyo en sus respectivos centros, que verosímilmente han sido interpretadas como bases para postes de madera, que serían la base para la construcción de un pequeño monumento funerario.

El hallazgo de tumbas (no las de perinatales o niños) en el interior de hábitats ha sido repetidamente leída como indicio de tumba heroica. La lectura que se da es la construcción de la tumba del

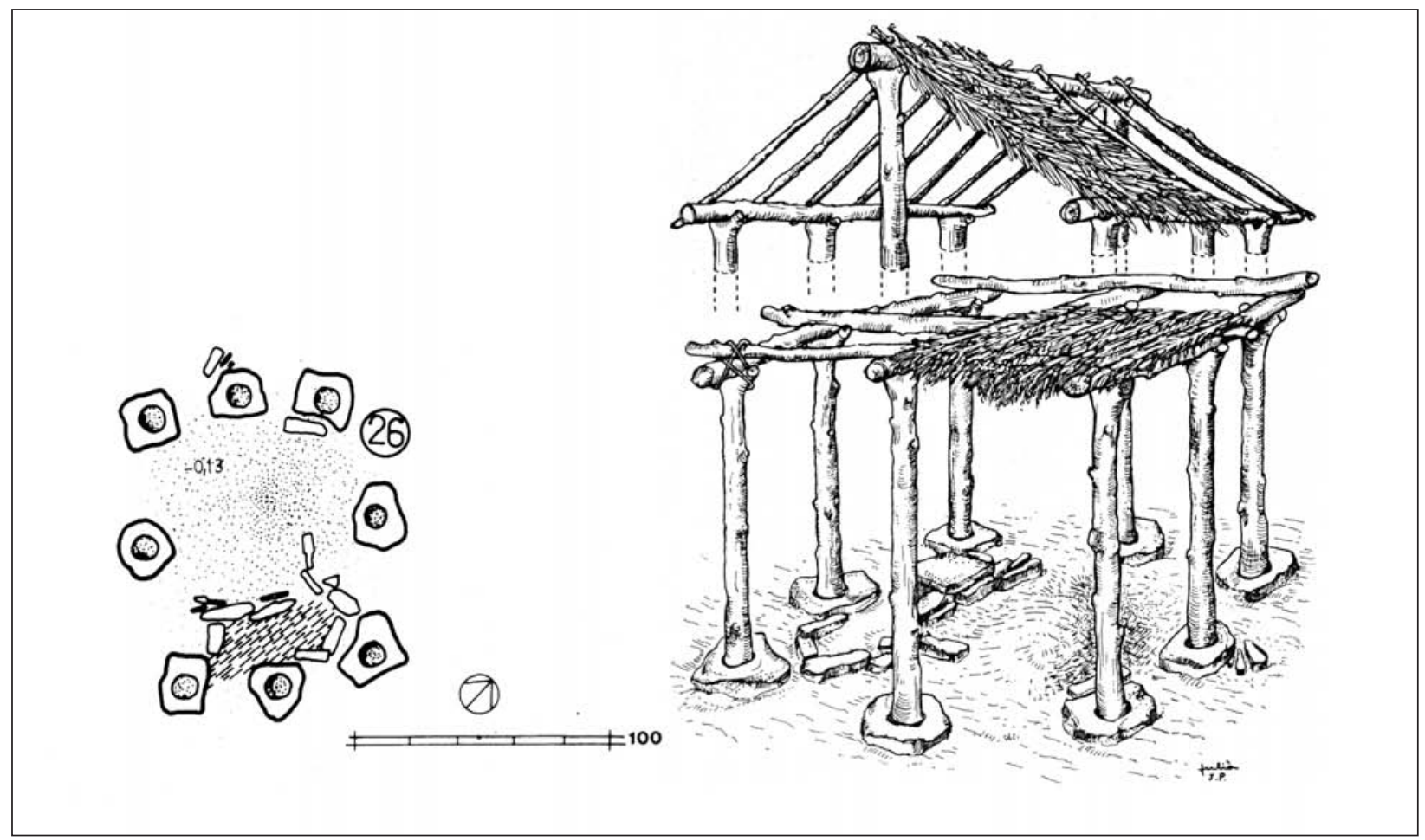

Fig 7.- Planta y reconstrucción de la sepultura 26 del sector Teulers de la necrópolis del Coll del Moro (Gandesa, Tarragona) (Rafel 1989: 101; Ferrer 1989: fig. 14).

35 Calars: Unitats 4; 7; 9. Teuler: Unitats 3; 17; La estructura también como un tipo de ofrenda; 36. Maries: Unitats 7; 26. pegada a T.22, identificada como T.24, se debe entender 
personaje heroizado en su residencia (Guaitoli 2004: 21), pero creo que debe ir más en relación con el concepto anteriormente planteado de la fundación mítica del grupo (y por extensión de la residencia). Al mismo tiempo, las dimensiones de las estructuras y la cantidad de piezas en sus ajuares son exageradamente grandes en comparación con el resto de tumbas de sus cronologías. Los ejemplos más claros, corresponden a contextos etruscos y griegos, destacando las inhumaciones de Piazza d'Armi en Veio (Lazi, Italia), Toumba (Eubea, Grecia) o Lefkandi (Eubea, Grecia), Lavinio (Lazi, Italia), Poseidonia (Campania, Italia), entre otros. El caso de Veio, donde la tumba se cubre con una gran cabaña y la posterior perduración del conjunto a pesar de las refacciones urbanísticas y viárias de la zona, que acaba durante la segunda mitad del s.VI AC (Bartoloni 2005: 71), dan buena prueba de la importancia del conjunto para la comunidad. De este conjunto destaca el carácter excepcional de la deposición a partir de que el recinto aparece señalizado, probablemente por una pequeña cabaña, miniaturizada, que encontraría paralelos según la autora (Bartoloni 2005: 71, n.57) en BorchenEttein en el Valle del Rin, así como también en la extraña tumba de la necrópolis del Coll del Moro de Gandesa.

Es cierto que las tumbas dentro de hábitat, no pueden ser consideradas directamente como heroa, ni como lugares de culto $^{36}$, pero por asimilación con otros ejemplos, no se puede evitar incluir como tales los siguientes ejemplos del nordeste peninsular : Coll del Moro de la Serra d'Almos a Tivissa y el « hallazgo cerrado » d'Ullastret.

Coll del Moro de Serra d'Àlmos (Tivissa): Situada en el extremo NE de la Serra de Tivissa, sobre el paso natural que une la Serra de Montsant con el Ebro y sobre el barranco de Mussefra (paso natural entre la Serra de Tivissa y el litoral). Su ubicación espacial se relaciona con la necrópolis destruida del poblado del Coll Alt de Tivissa (Cela et al. 1999: 92). La tumba se descubrió en la parte SE del poblado, formando un pequeño túmulo de $5 \mathrm{~m}^{2}$ por $90 \mathrm{~cm}$ de alto. El tipo de enterramiento corresponde a una inhumación atípica, tanto por lo que representa dentro de la norma del ritual funerario en el noreste peninsular, donde domina de manera exclusiva la cremación; como por la forma de la inhumación, deposición boca abajo con un brazo flexionado bajo el pecho. La atribución de tal enterramiento como verdadera estructura de carácter funerario ha sido recientemente puesta en duda, debido en parte a la excepcionalidad de su estructura y a la articulación de un complejo ajuar (26 piezas cerámicas, abundantes piezas para tejer y distintos elementos metálicos de ornamentación

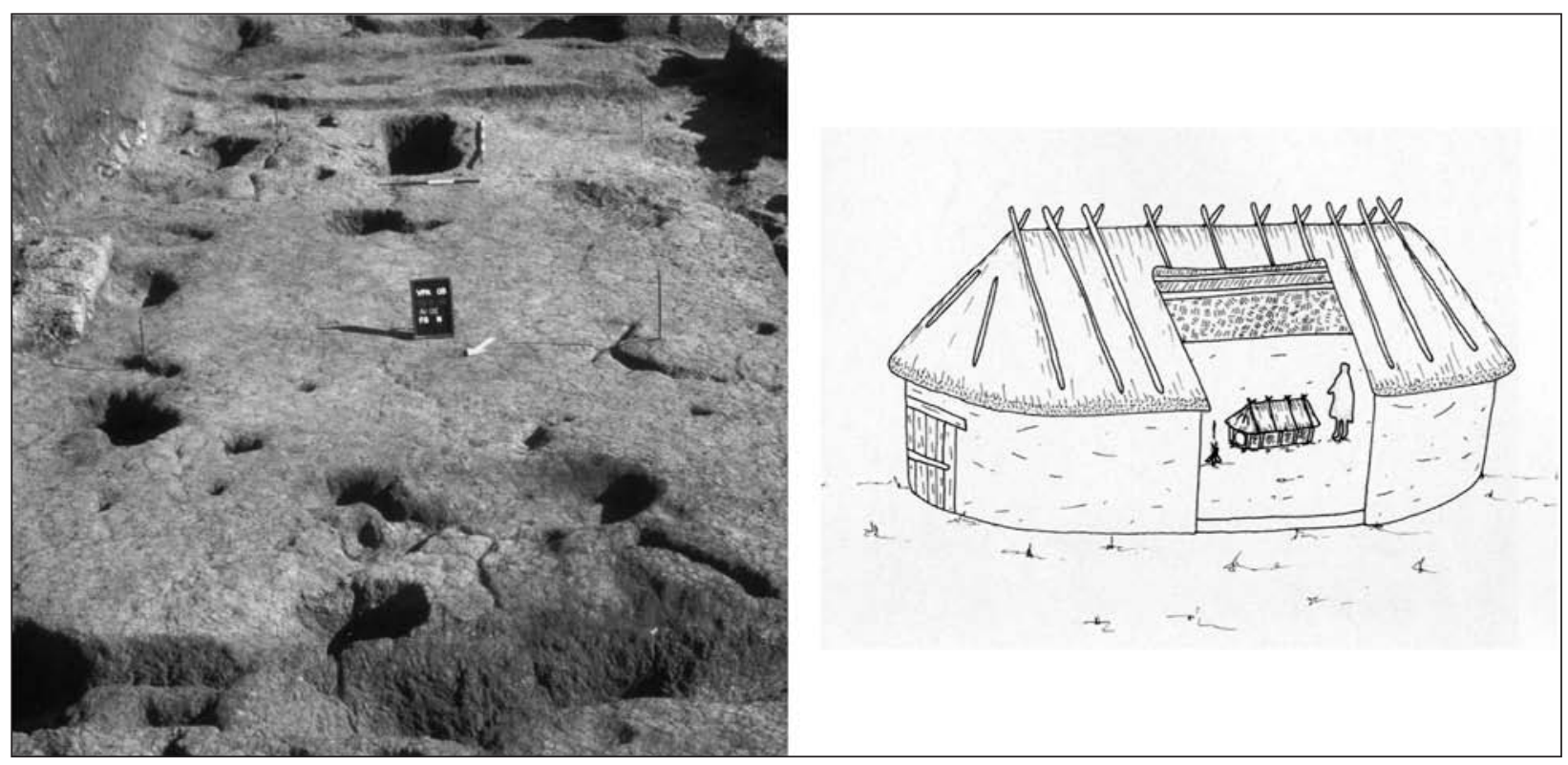

Fig 8.- Fotografía y reconstrucción de la "capella funeraria” de Veio-Piazza d'Armi (Bartoloni 2005: fig. 7 y 10).

36 Menos aún si consideramos que, por ejemplo, el caso de lente o bien como muerto sacro (Bartoloni 2005: 71). Veio ha sido leído en una dicotomía entre personaje exce- 
personal y herramientas ${ }^{37}$ ) (Cela et al. 1999: 108). La poca distancia temporal entre el final del poblado y la sepultura, como lo demuestran los materiales, indica una innegable selección del lugar para depositar el difunto. Esta ubicación, reproduce la relación entre el héroe fundador y la comunidad. En el momento de su deposición, la tumba se convierte en una tumba aislada, hecho que refuerza las premisas y los diferentes indicadores simbólicos del culto heroico.

Ullastret: me refiero al conocido "hallazgo cerrado" del que hablaron A.Arribas (Arribas y Trias de Arribas 1961) y E.Sanmartí (1982). Se trata de un lote de cerámicas, piezas metálicas (escorias de hierro y materiales fundidos), huesos quemados (sin poder confirmar si son humanos o no) y cenizas halladas en los estratos VIIIb del corte L5B de la excavación Oliva 1959. Los materiales, todos encuadrables en la primera mitad del s.VI AC, se documentan de manera semidispersa en toda el área excavada, proponiéndose que se tratase de una tumba (Arribas y Trias de Arribas 1961; Sanmartí 1982b) destruida al preparar el terreno para edificar las posteriores construcciones. A pesar de las dudas que plantea su atribución directa como tumba debido a la dispersión de los materiales (Arribas y Trias de Arribas 1961: 20), el conjunto es homogéneo y la asociación de los materiales corresponde perfectamente con los ajuares cerámicos que se documentan en el noreste de Cataluña y el sur de Francia en el mismo período. El conjunto presenta una fuerte componente etrusca (taza antropoprosopa etrusco-corintia, ánfora etrusca y kantharos en Bucchero Nero), junto a otras importaciones como un olpe jonio junto a piezas locales realizadas a mano. Estas cerámicas a mano no son extrañas como urnas contenedoras de los despojos en las necrópolis del noreste de Cataluña y del Sur de Francia. De este modo, este

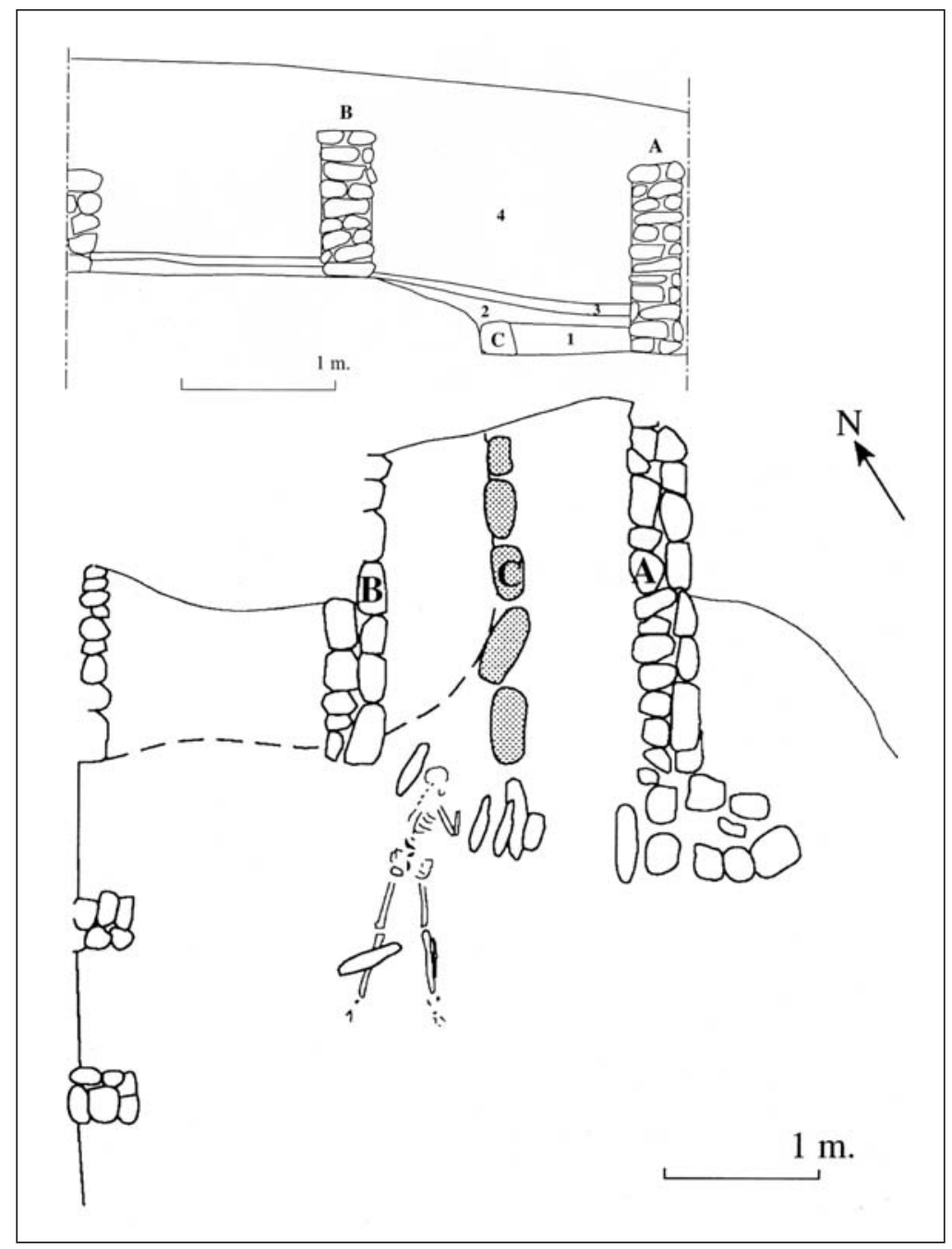

Fig 9.- Planta y sección de la sepultura del túmulo del Coll del Moro (Serra d'Àlmos, Tarragona) (Reelaboración a partir de Cela, Noguera y Rovira 1999: Fig.2).
37 Recordemos que la presencia de instrumental en tumbas toma connotaciones de indicación de rol social. Especialmente el hacha, tiene una fuerte componente sacra en todo el ámbito itálico, balcánico y francés (Bartoloni 2003; Janin 2000: 127). La presencia de hachas en tumbas, se documenta pocas veces en la Europa protohistórica, y siempre en tumbas de alto estatus socio-económico: además del túmulo de Coll del Moro Serra d'Àlmors, también se documentan en Sant'Abbondio di Pompei t.8; BolognaBenacci Caprara t.39, t.53; Tomba del Duce a Vetulonia;T.68 de G.B.II de Mailhac; Tomba a cista del parco dei Monaci cerca de Matera; Pontecagnano t.926, t.928; Túmulo de Timpone delle Rose nella Sila; Tumba del guerrero de
Neheren a Tübingen; T.1975/131 de Hagenau; Vetralla Poggio-Montano T15; Tarquinia Arcatelle T3 i T34; Cerveteri Sorbo T.283; Populonia Poggio del Molino; Tomba A de Verrucchio-necropoli Lippi; T2/1980 de Verona necropoli della Colombara di Gazzo Veronese; Tumba de la "tapadera figurada" de Sticna; Veio Casal del Foso T.1038, T.1073; Veio Grotta Gramiccia t.146; Pontecagnano t.4461;Pitino-San Severino t.31; necropoli Benadduci, Tolentino t.23; Este-Ricovero t.236; Randi t.14; Pithecoussai t.515, t.557, t.678; Casa Nocera a Casale Marittimo (las tumbas masculinas); Tumba de Lusehof (Voldtofte); Tumba de Oss; entre otros ejemplos. 
conjunto correspondería a una tumba dentro del hábitat, de una fase anterior a la construcción de la muralla (según Arribas y Trias de Arribas: 1961).

A pesar de la relativa distancia espacial y temporal, no se puede eludir el túmulo ibérico de Azaila (Beltrán-Lloris 1995). Que supone en toda regla, el modelo de heroon de tipo clásico. Presentándose en uno de los accesos de la ciudad, con un rico ajuar y un elevado número de ofrendas sobre el túmulo. Esta muestra, permite aceptar que el modelo de tumbas singulares en poblados $\mathrm{u}$ oppida, es un modelo que se repite en todo el nordeste peninsular a lo largo de un basto espacio temporal, como reflejo de un imaginario común.

\section{Conclusiones:}

Las tumbas de guerreros y las tumbas que pueden recrear un imaginario heroico aparecen de forma escasa en el territorio, prácticamente únicas en sus respectivos contextos. $\mathrm{Al}$ mismo tiempo, no son frecuentes los hallazgos de elementos de prestigio en las mismas necrópolis, también de manera casi única (Mas de Mussols T.9 y T.18; Agullana t.184 y t.192; Anglès t.8; Pézenas t.47). Creo que no es inocente ni casual. El problema que surge es saber si los dos tipos de tumbas (de guerreros y con elementos de prestigio) son coetáneas o no. En el caso de que lo fueran nos hallaríamos delante de una dualidad de poderes dentro de las distintas comunidades, que se manifestarían en base a atributos particulares: armas y elementos de prestigio (principalmente relacionados con el banquete Guaitoli 2004-), fenómeno que al mismo tiempo estructuraría la sociedad en grupos. Pero en el caso de que siguieran una diacronía, no se podría desligar la emergencia de una aristocracia militar de un fenómeno de complicación del sistema y de la estructura social. Sin duda el momento de irrupción de estas elites militares coincidiría con la necesidad de asegurar los territorios y organizar nuevos sistemas comerciales que se manifestarían con la presencia desmesurada de productos importados a partir de este momento. La afirmación de este sistema de control por la fuerza, en base a una jerarquía de la población coincide con la adopción de una serie de comportamientos circunmediterráneos como se observa fundamental y claramente

38 Entendiendo como región el espacio que agrupa una série de asentamientos.

39 Aunque ya desde el Bronce Final se empieza a diferenciar entre distintos grupos arqueológicos regionales, no se puede con los elementos importados y el ritual del symposion. Es con la presencia de estas evidencias de celebraciones de banquetes aristocráticos cuando definitivamente se considera consolidado el momento de las aristocracias guerreras, que abandonarán el uso de las armas por los placeres y las comodidades del comercio y las transacciones y relaciones regladas. Seguramente la ausencia generalizada de armas a partir de mediados del s.VaC permite pensar en una organización suprarregional $^{38}$, que aseguraría la tranquilidad. Este momento correspondería también al período de formación de las étnias ibéricas del nordeste peninsular (ilergetes, layetanos, indiketas.... $)^{39}$. La unión que permite organizar y explotar territorios más amplios acaba creando un código común que caracteriza con el paso del tiempo cada una de estas regiones.

Las múltiples posibilidades que ofrece el culto heroico, quedan manifiestas en el registro funerario de Cataluña: tumbas aisladas, Heroa, representaciones heroicas, jeraquización de las armas, que corresponde al mismo tiempo a una jerarquización socio-militar; o símbolos (espadas; espadas miniaturizadas; elementos de caza; etc.). Su aparición no es un hecho casual ni en el tiempo ni en el espacio. El s. VI AC y el noreste peninsular se combinan y cada vez se está descubriendo una mayor cantidad de intercambios mediterráneos. La llegada y consolidación en territorio catalán de poblaciones foráneas revoluciona, junto a su comercio y sistema de intercambios, las forma de exhibición de los símbolos del poder, y modifica también las formas de organización social (Sanmartí 2001) y el imaginario local.

I.Morris habló de un conflicto ideológico entre las estructuras aristocráticas de la Edad Oscura (Dark Age) y el posterior sistema basado en la emergencia de la polis, para explicar la emergencia del culto heroico (Morris 1988). Aquí, la existencia de este culto, aparece con los contactos coloniales, en un momento en que se transforman los sistemas del bronce final para constituir unas sociedades (pre) urbanas. Cada vez, pues, parece más clara la repercusión que tuvo la obra homérica en los territorios no griegos (Snodgrass 1982). A los ya clásicos ejemplos de Pithecoussai y Sicilia (Antonaccio 1999), se debe añadir una influencia en el registro material de ciertos elementos de la protohistoria

considerar el problema de la etnicidad hasta bien entrado el s.V aC. No pasa lo mismo en otros territorios ibéricos, donde sus períodos de formación se articulan en distintos momentos con influencias y substratos diversos. 
catalana $^{40}$. De este modo debemos considerar que la forma de representar al héroe en Cataluña toma ideas del imaginario homérico.

Aceptar pues la existencia de cultos heroicos no implica un tipo de organización suprarreginal o estatal, aunque en ciertos aspectos indique el inicio de estos procesos. Este proceso aporta nuevas luces respecto a la enorme diversidad a que nos enfrentamos a la hora de estudiar el momento que comprende desde el orientalizante final y su tránsito hacia la cultura ibérica, con múltiples maneras de estructurar, entender y explotar la sociedad y el territorio. Quedando clara, de este modo, la enorme influencia colonial en las formas de manifestar y legitimizar el poder en las sociedades protohistóricas catalanas, al repetir, bajo una adaptación local, imaginarios de carácter universal.

\section{Bibliografía:}

ADAM, A.M. (1992): «Signification et fonction des fibules dans le cadre des relations transalpines du VIIe au Ve siècle avant notre ère», dins L.Aigner (coord.): Etrusker nördlich von Etrurien, 1989, 389-409, 1992.

ALMAGRO-GORBEA, M. (1992): "Los intercambios culturales entre Aragón y el litoral mediterráneo durante el Bronce Final". Aragón/Litoral Mediterráneo: Intercambios Culturales durante la Prehistoria. 633-658.

AMPOLO, C. (1977): "Demarato. Osservazioni sulla mobilità sociale arcaica”. Dialoghi di Archeologia, 9-10, 333-345, 1977.

ANGLES, M., GIANNI, A. (1985): "La morte ineguale: dinamiche sociali riflesse nel rituale funerario. Il caso della necropoli dell'età del ferro di Caracupa", Opus, IV, 179-215, 1985.

ANTONACCIO, C.M. (1994): "Contesting the Past: Hero Cult, Tomb Cult, and Epic in Early Greece", AJA,Volume 98 No. 3, 1994, 389-411.

ANTONACCIO, C.M. (1995): An Archaeology of Ancestors: Tomb Cult and Hero-Cult in Early

\footnotetext{
40 Véase por ejemplo los colgantes de bronce zoomorfos de tipo "carnero", que tenemos que relacionar, al margen de las propuestas interpretativas sobre el carnero como animal totémico del hogar (Bea 1996; Maluquer 1987; Rafel 1997), con el imaginario greco-homérico (Graells y Sardà 2005 y 2007). El pasaje de la Odisea con la huída de Ulíses bajo la piel de una oveja (o carnero) convertiría a este animal, en un símbolo de protección, especialmente significativo en ritos de pasaje como el muerte. De esta manera, el cambio de estado entre vivo y muerto se convierte en un perfecto espa-
}

Greece.

ANTONACCIO, C.M. (1999): "Colonization and the origins of hero cult", dins R.Hägg (Ed.): Ancient Greek Hero Cult, Proceedings of the fifth International Seminar on Ancient Greek Cult, organized by the Department of Classical Archaeology and Ancient History, Göteborg University, 21-23 April 1995, Acta Instituti Atheniensis Regni Sueciae, Series in $8^{\circ}$, XVI, 109-121, Stockholm.

ARRIBAS, A., TRIAS de ARRIBAS, G. (1961): "Un interesante "hallazgo cerrado" en el yacimiento de Ullastret”, AEspA, XXXIV, 18-40.

AZZAROLI, A. (1980): "Venetic Horses from Iron Age burials at Padova", RSP, XXXV, 281-310.

BARTOLONI, G. (1984): "Riti funerari dell'aristocrazia in Etruria e nel Lacio. L'esempio di Veio", Opus, III, 13-29, 1984.

BARTOLONI, G. (1993): "Documentazione figurata e deposizioni funerarie: le tombe con carro". Archeologia Classica, 45, 1, 271-287, 1993.

BARTOLONI, G. (2002): “Appunti sull'introduzione del banchetto nel Lacio: La coppa del principe", en M.G.Amadasi, M.Liverani, P.Matthiae (a cura di): Da Pyrgi a Mozia. Studi sull'archeologia del Mediterraneo in memoria di Antonia Ciasca, Roma, 57-68, 2002.

BARTOLONI, G. (2003): Le società dell'Italia primitiva. Lo studio delle necropoli e la nascita delle aristocrazie. Roma, 2003.

BARTOLONI, G. (2005) Una cappella funeraria al centro del pianoro di Piazza d'Armi - Veio, AION ns 9-10 (2002-2003), 63-78.

BELTRAN-LLORIS, M. (1995): Azaila. Nuevas aportaciones deducidas de la documentación inédita de Juan Cabré Aguiló. Instutución "Fernando el Católico", Zaragoza.

BENTINI, L., NERI, D. (2002): “Il rito funebre: ricostruzioni ed ipotesi”, en P.Von Eles (a cura di): Guerriero e sacerdote. Autorità e comuni-

cio que asimila el mito de abandonar el peligro del "interior" de la cueva de Polifemo.

De igual manera podríamos considerar la aparición de vasos para el consumo de bebidas de prestigio. Algunos de los cuales, en ámbito itálico, se han relacionado con las leyendas homéricas (recordemos la famosa copa de "Nestor" de Pithecoussai, donde aparece un texto en griego, con un pasaje de la Ilíada). Así, la continua llegada de productos de carácter mediterráneos, traería también con ellos leyendas y tradiciones orientales. 
tà nell'età del ferro a Verrucchio. La Tumba del Trono. Quaderni di Archeologia dell'Emilia Romagna, 6, Bologna, 2002, 29-30.

BIETTI-SESTIERI, A.Ma. (1992): La necropoli laziale di Osteria dell'Osa, Roma, 1992.

BIETTI-SESTIERI, A.Ma., De SANTIS, A., SALVADEI, L. (1988): "The relevance of anthropological data for the identification of uncommon social roles: the case of the Iron Age cemetery of Osteria dell'Osa (Rome)", in Atti del Simposio Internazionale. Physical Anthropology and prehistoric Archeology. Supplemento alla Rivista di Antropologia, LXVI, 349-380, 1988.

BIETTI-SESTIERI, A.Ma., De SANTIS, A. (2000): Protostoria dei popoli latini, Museo nazionale romano, terme di Diocleziano, Electa, Napoli.

BIETTI-SESTIERI, A.Ma., De SANTIS, A. (2003): "Il processo formativo della cultura Laziale", Atti della XXXV riunione scientifica: "le comunità della preistoria italiana, studi e ricerche sul neolitico e le età dei metalli" In memoria di Luigi Bernabó Brea, Firenze, 745763.

BOIARDI, A., Von ELES, P. (1997): "La necropoli Lippi di Verrucchio. Ipotesi preliminari per una analisi delle strutture sociali”, Archeologia dell'Emilia Romagna, I, Bologna, 1997, 23-40.

BOISSON, H., CHARDENON, N. (2002): «Mobilier céramique et métallique de prestige? La nécropole du Grand-Bassin I à Mailhac (Aude) VIIIe-VIIe S.av.n.è.», in Pratiques funéraires protohistoriques entre Massif central et Pyrénées. Nouvelles données, Actes du Colloque en hommage à J-F.Salinier (Puylaurens 2000), Archéologie Tarnaise, 12, 111-119.

BOUZEK, J. (1997): Greece, Anatolia and Europe: Cultural interrelations during the early Iron Age, Studies in Mediterranean Archaeology, CXXII, Paul Aströms Förlag.

BRUNI, S. (2000): “L'architettura tombale dell' area costiera dell'Estrema Etruria settentrionale. Apunti per l'Orientalizzante antico e medio", in A.Zifferero (a cura di): L'architettura funeraria a Populonia tra IX e VI secolo a.C., atti del Convengo Castello di Populonia 30-31 ottobre 1997, Quaderni del dipartimento di archaeologia e storia delle arti sezione archeo$\operatorname{logica} 47,151-172$.
BURANELLI, F. (1979): “Utensili per la lavorazione del legno in due tombe villanoviane da Veio", Arch.Class., XXXI, 1-17.

CABRÉ, J. (1942): "El Thymiaterion céltico de Calaceite”. AEspA, XV, 181-198.

CAMPILLO, D. (1993): “Annex: Estudi antropològic", in E.Sanmartí 1993: Una tomba de guerrer de la primera edat del ferro trobada a Llinars del Vallès (Vallès Oriental, Barcelona), treballs del MDG, 1 .

CELA, X., NOGUERA, J., ROVIRA, C. (1999): "Els materials arqueològics del jaciment ibèric del Coll del Moro de Serra d'Almos (Tivissa, Ribera d'Ebre). Col·lecció del Museu Comarcal Salvador Vilaseca de Reus", Pyrenae, 30, p.91121.

CERDEÑO, Ma.La., GARCÍA-HUERTA, R. (1990): "Las necrópolis de incineración del Alto Jalón y el Alto Tajo", in F.Burillo (Coord): II Simposio sobre los celtíberos: Necrópolis Celtibéricas, Zaragoza, 75-92.

CHAUME, B., OLIVIER, L., REINHARD, W. (2000): «L'enclos hallstattien de Vix "Les Herbues": un lieu cultuel de type aristocratique? », MAM, 7, Actes du Colloque International de Carcassone: Mailhac et le Premier Âge du Fer en Europe Occidentale, Hommages à Odette et Jean Taffanel, 311-327.

CLAUSELL, G. (2002-2003): "Un escarabeo etrusco en la necrópolis del Torrelló del Boverot (Almassora, Castelló)", Quad.Preh.Arq.Cast., 23, 241-246.

COLDSTREAM, J.N. (1976): "Hero-cults in the age of Homer", JHS, 96, 8-17.

COLDSTREAM, J.N. (1993): "Mixed marriages at the frontiers of the early greek world", Oxford Journal of Archaeology, 12 (1), 1993, 89-107, 1993.

COLET, A., GENÉ, M., GIP (2005): El món funerari durant el Grup del Segre-Cinca III (950750 cal a.n.e.): la necròpolis de Roques de Sant Formatge (Seròs, el Segrià)", RAP 15, 151163.

COLONNA, G., Von HASE, F. (1986): “Alle origini della statuaria etrusca: la tomba delle statue presso Ceri”, St.Etr., 52, 13-59.

COLONNA, G. (2000): "Populonia e l'architettura funeraria etrusca", in A.Zifferero (a cura di): L'architettura funeraria a Populonia tra IX $e$ VI secolo a.C., atti del Convengo Castello di 
Populonia 30-31 ottobre 1997, Quaderni del dipartimento di archaeologia e storia delle arti sezione archeologica 47, 253-260.

CUOZZO, M. (2003): Reinventando la Tradizione : Immaginario sociale, ideologie e rappresentazione nelle necropoli orientalizzanti di Pontecagnano. Pandemos, Paestum.

CUPITO, M. (2004): “Necropoli Lachini Pelà: rilettura critica dei dati ottocenteschi”, en Leonardi, G. (a cura di), La tomba bisoma di uomo e di cavallo nella necropoli del Piovego-Padova, Venezia, 36-40.

DEDET, B. (2000) : «Images sociales de la mort dans le Sud-Est de la France au Premier Âge du Fer », MAM, 7, Actes du Colloque International de Carcassone: Mailhac et le Premier Âge du Fer en Europe Occidentale, Hommages à Odette et Jean Taffanel, 133-155.

DEDET, B. (2001): Tombes et practiques funéraires protohistoriques des Grands Causses $d u$ Gévaudan. DAF, 84. Éditions de la maison des Sciences de l'Homme. Paris.

DETIÈNNE, M. (1979): « Il coltello da carne », Dialoghi di archeologia, NS I, 6-16.

ELUÈRE, C. (1982): Les ors préhistoriques. L'âge du bronze en France, 2, Picard. Paris.

EGG, M. (2004): "I guerrieri", F.Marzatico i P.Gleirscher (A cura di): Guerrieri, principi ed eroi fra il Danubio e il Po, dalla preistoria all'alto medioevo, Trento, 35-55.

FARNIÉ, C., QUESADA, F. (2005), Espadas de hierro, grebas de bronce símbolos de poder e instrumentos de guerra a comienzos de la Edad de Hierro en la península ibérica, Murcia.

FERRER, M. (1989): “Un sepulcre singular a la necrópolis del Coll del Moro (Gandesa, Tarragona). Observacions sobre el paisatge i les pràctiques funeràries", Ampúrias, 48-50, 312-323.

GAMBACURTA, G., TIRELLI, M. (1996): "Le sepolture di cavallo nella necropoli $L e$ Brustolade", in La protostoria tra Sile $e$ Tagliamento. Antiche genti fra Veneto e Friuli, Catàleg de la mostra, Pàdova, 71-74.

GAMBARI, F.M., TECCHIATI, U. (2004): "Il cane e il cavallo come indicatori di status nella preistoria e nella protostoria", F.Marzatico y P.Gleirscher (A cura di): Guerrieri, principi ed eroi fra il Danubio e il Po, dalla preistoria all'alto medioevo, Trento, 231-241.
GARCÉS, I. (2002ª): “93. Morrió de cavall”, in J.LL.Ribes (a cura de): Sala d'arqueologia, Catàleg, QSA, 2, 198-199.

GARCÉS, I. (2002b): "94. Fre de cavall", in J.LL.Ribes (a cura de): Sala d'arqueologia, Catàleg, QSA, 2, 200-201.

GJERSTAD, E. (1979): "A Cypro-Greek royal marriage in the 8th cent. B.C.", in Studies presented in memory of Porphyrios Dikaios, Nicosia, 89 i ss., 1979.

GRAELLS, R. (2004): "Indicis d'emergència aristocràtica en el registre funerari del nord-est peninsular. La tomba Agullana 184", R.A.P., 14, 61-83, Lleida.

GRAELLS, R. (2006): "La vaixella metàl-lica del nord est peninsular (s.VII - V AC)", Cypsela $16,195-211$.

GRAELLS, R. (2007): “Espadas miniaturizadas en las necrópolis del nordeste de la Península Ibérica", M.M., 48, 140-153.

GRAELLS, R. (ep.a): "Indicios de emergencia aristocrática en el registro funerario del nordeste peninsular. La tumba 184 de Agullana", dins IV Congreso de Arqueología Peninsular: Orígen y desarrollo inicial de la desigualdad en la Prehistoria Reciente de la Peníncula Ibérica, Faro.

GRAELLS, R. (ep.b): La necròpolis protohistòrica de Milmanda (Vimbodí, Conca de Barberà, Tarragona). Un exemple del món funerai català durant el trànsit entre els segles VII $i$ VI AC, Hic et Nunc, Tarragona.

GRAELLS, R., SARDÀ, S. (2005), "Entre carneros, palomas y ciervos: la asimilación de estímulos mediterráneos a través de la toréutica. El ejemplo del noreste de la Península Ibérica durante el s.VI AC", RSL LXXI, 5-28.

GRAELLS, R., SARDÀ, S. (2007), “Los colgantes zoomorfos, un ejemplo del nuevo repertorio toréutico del s.VI AC del nordeste peninsular", in L.Abad y J.A.Soler (Eds.): Actas del congreso Arte Ibérico en la España Mediterránea (Alicante 24-27 octubre 2005), 265-275.

GUAITOLI, M.T. (2004): "La dimensione di guerriero, principe ed eroe attraverso le fonti letterarie e le testimonianze archeologiche", F.Marzatico y P.Gleirscher (A cura di): Guerrieri, principi ed eroi fra il Danubio e il Po, dalla preistoria all'alto medioevo, Trento, 17-34. 
GUILAINE, J., ZAMMIT, J. (2002): El camino a la guerra. La violencia en la prehistoria. Ariel Prehistoria, Barcelona.

HODDER, I. (1987): "La Arqueología en la Era Post-Moderna", TP, 44, 11-26.

HODOS, T. (1999): "Intermarriage in the western Greek colonies", Oxford Journal of Archaeology, 18.1, 61-78, 1999

HUGHES, D.D. (1999): "Hero cult, heroic honors, heroic dead: some developments in the Hellenistic and Roman periods", dins R.Hägg (Ed.): Ancient Greek Hero Cult, Proceedings of the fifth International Seminar on Ancient Greek Cult, organized by the Department of Classical Archaeology and Ancient History, Göteborg University, 21-23 April 1995, Acta Instituti Atheniensis Regni Sueciae, Series in $8^{\circ}$, XVI, 165-175, Stockholm.

HUMPHREYS, S.C. (1980) "Family tombs and tomb cult in ancient Athens: tradition or traditionalism?" JHS, 100, 96-126.

IAIA, C. (1999): Simbolismo funerario e ideologia alle origini di una civiltà urbana. Forme rituali nelle sepolture "villanoviane" a Tarquinia e Vulci, en el loro entroterra, GcePdPI, 3, Firenze.

JANIN, Th. (2000): Nécropoles et sociétés Élisyques: les communautés du Premier Âge du fer en Languedoc Occidental, MAM, 7, Actes du Colloque International de Carcassone: Mailhac et le Premier Âge du Fer en Europe Occidentale, Hommages à Odette et Jean Taffanel, 117-131.

JUNYENT, E., PÉREZ, A. (2003): L'antiguita, d'Iltirta a Ilerda, Història de Lleida, vol.I, Pagès Editors, Lleida.

LA GENIÈRE, J. DE (1997) “Appendice: Note sur une muserolle disparne", In Héra. Images, espaces, cultes, Actes de Collaque International de Lille (1993), Naple, Coll CJB, 15, 261-265.

LAMBRINOUDAKIS, V.K. (1988) "Veneration of Ancestors in Geometric Naxos. In: R.Hägg, N.Marinatos, and G. C.Nordquist (eds) Early Greek Cult Practice, pp. 235-245. Skrifter utgivna av svenska institutet i Athen, vol. 38. Stockholm.

LEONARDI, G. (1990): "L'area archeologica del C.U.S.-Piovego, Padova: relazione preliminare della campagna di scavo 1989, con note metodologiche", $Q A V$, VI, 11-53.
LEONARDI, G. (a cura di) (2004): La tomba bisoma di uomo e di cavallo nella necropoli del Piovego-Padova, Venezia.

LEONELLI, V. (2003): La necropoli della prima età del ferro delle Acciaierie a Terni, Contributi per un'edizione critica, GCPdPI, 7.

LILLIOS, K.T. (1999): "Objects of memory: The etnography and archeology of Heirlooms", Journal of Archeological Method and Theory, vol.6, n.3, 235-262.

LISSARRAGUE, F. (1988): "La stèle avant la lettre", B.D'Agostino (Dir.): Atti del Colloquio Internazionale di Capri: La Parola, L'immagine, La tomba, AION ArchStAnt, X, 97-105.

LOUIS, M., TAFFENEL, O. et J. (1958) : Le Premier Âge du Fer Languedocien, les nécropoles à incinération, Collection de Monographies préhistoriques et archéologiques, Inst.Int.d'Ét.Ligures, Bordighera-Montpellier.

LUCAS, R. (2005): "Narigón y ronzal "versus" bocado de caballo: el arrastre de los équidos", Gladius 24, 99-108.

MAGGIANI, A., RIZZO, A.M. (2001): “Area sacra in località Sant'Antonio", in A.M.Sgubini Moretti (a cura di): Veio, Cerveteri, Vulci: città a confronto. Catalogo della mostra. Roma, 2001, 143-145.

MANCEBO, J. (2000): “Análisis de los objetos metálicos en el período orientalizante y su conexión con el mundo fenicio. Los cuchillos afalcatados". Atti del IV Congresso Internazionale di Studi Fenici e Punici, Cádiz, 1825-1834.

MANFREDINI, A. (1994): "La sepoltura del cavallo a Maccerese (RM): una premessa archeologica”, Origini, XVIII, 291-296.

MARINI, A. (2003): “...e lo fece bruciare con le sue armi belle. Status del guerriero e rituale funerario nella Grecia della prima età del Ferro: tombe con armi nelle necropoli di Atene e Lefkandi”, $R d^{\prime} A$, XXVII, 21-56.

MAZARAKIS, A. (1999): "Reflections on hero cult in Early Iron Age Greece", en R.Hägg (Ed.): Ancient Greek Hero Cult, Proceedings of the fifth International Seminar on Ancient Greek Cult, organized by the Department of Classical Archaeology and Ancient History, Göteborg University, 21-23 April 1995, Acta Instituti Atheniensis Regni Sueciae, Series in $8^{\circ}$, XVI, 9-36, Stockholm. 
McCAULEY, B. (1999): "Heroes and Power: The politics of Bone Transferal", in R.Hägg (Ed.): Ancient Greek Hero Cult, Proceedings of the fifth International Seminar on Ancient Greek Cult, organized by the Department of Classical Archaeology and Ancient History, Göteborg University, 21-23 April 1995, Acta Instituti Atheniensis Regni Sueciae, Series in $8^{\circ}$, XVI, 85-98, Stockholm.

MÉNIEL, P. (2002): "Les animaux dans les rites funéraires au deuxième àge du fer en Gaule septentrionale", Anthropozoologica, 35, 3-15.

MESADO, N., SARRIÓN, I. (2000): “Un enterramiento insólito: el caballo ibérico de la Regenta", Conmemoración del XXX aniversari del Museu Arqueològic comarcal de la Plana Baixa (1967-1997), Borriana, 89-101.

MORRIS, I. (1987): Burial and Ancient Society. The Rise of the Greek city-state, Cambridge.

MORRIS, I. (1988): “Tomb Cult and 'Greek Renaissance: The Past and Present in the 8th c. B.C." Antiquity 62: 750-61

MURRAY, O. (1988): Death and the symposion, Atti del Colloquio Internazionale di Capri: La parola, l'immagine, la tomba, AION ArchStAnt X, Napoli, 239-257, 1988.

NENCI, G. (1994): "Qualche considerazione sulla necropoli come fonte storica nell'antichità," en Actes du colloque international du Centre de Recherches Archéologiques de l'Université de Lille III (1991): Nécropoles et sociétés antiques (Grèce, Italie, Languedoc), 9-14.

NICKELS, A.(1989): Agde, la nécropole du premier âge du fer, R.A.N., supp.19.

OLMOS, R. (2002-2003) : "En la flor de la Edad. Un ideal de representación heroico iberohelenístico", CUPAUAM, 28-29, 259-272.

PACCIARELLI, M. (2001): Dal villaggio alla città. La svolta protourbana del 1000 a.C. nell'Italia tirrenica, Grandi Contesti e Problemi della Protostoria Italiana, 4, Firenze, 2001.

PAJOT, B. (1972): "Note sur deux tumuli et un dolmen de la region de Cazals (Tarn-et-Garone)", TIAP, XIV, 429-433.

PAULI, J.P. (1977): "Zur Hallstattkultur im RheimMain.Gebiet”, Fündberichte aus Hessen, 15, 213-227.

PERONI, R. (2004): “Culti, comunità tribali e gentilizie, caste guerriere e figure di eroi e principi nel secondo millenio in Italia tra Europa cen- trale ed Egeo", F.Marzatico y P.Gleirscher (A cura di): Guerrieri, principi ed eroi fra il Danubio e il Po, dalla preistoria all'alto medioevo, Trento, 161-174.

PLENS, M. (1986): La necròpolis de la Pedrera, Tèsi de Llicenciatura, inèdita, Lleida.

PLENS, M. (2002): “154. Estela antropomorfa funerària", in J.LL.Ribes (a cura de): Sala d'arqueologia, Catàleg, QSA, 2, 296-297.

PLENS, M., RAFEL, N. (2002): “La necròpoli de la Pedrera (Vallfogona-Termens)", in J.LL.Ribes (a cura de): Sala d'arqueologia, Catàleg, QSA, 2, 255-256.

POUZADOUX, C. (1993): "Les funerailles de Patrocle ou la mise en image des indices de la gloire", R.Olmos y J.A.Santos (Eds.): Iconografía Ibérica, Iconografía Itálica: propuestas de interpretación y lectura. Seria Varia UAM, 3, 137-152.

QUESADA, F. (1989): "La utilización del arco y la flecha en la Cultura Ibérica". Trabajos de Prehistoria, 46, 161-201.

QUESADA, F. (1994): “Lanzas hincadas, Aristóteles y las estelas del Bajo Aragón", V Congreso Internacional de Estelas Funerarias, I, Soria, 361-369.

QUESADA, F. (1997): El armamento ibérico. Estudio tipológico, geográfico, funcional, social y simbólico de las armas en la Cultura Ibérica (s.VI-Ia.C.), Monographies Instrumentum 3, 1997.

QUESADA, F. (2005): "El gobierno del Caballo montado en la antigüedad clásica con especial referencia al caso de Iberia. Bocados, espuelas y la cuestión de la silla de montar, estribos y herraduras", Gladius, XXV, 97-150.

RAFEL, N. (1985): "El ritual d'enterrament ibèric. Un assaig de reconstrucció", Fonaments, 5, Barcelona, 1985, 13-31.

RAFEL, N. (1989): La necrópolis del Coll del Moro de Gandesa: Les estructures funeràries, Publicacions de l'Ajuntament de Tarragona, Col·lecció Monografies 1.

RAFEL, N. (1991): La necrópolis del Coll del Moro de Gandesa. Els materials, Publicacions de la Diputació de Tarragona, 1991.

RAFEL, N. (1993): Necròpolis del Coll del Moro (Gandesa, Terra Alta). Campanyes del 1984 al 1987. Excavacions Arqueològiques a Catalunya, 12, Bcn. 
RAFEL, N. (1997): "Colgantes de bronze paleoibéricos en el NE de la Península Ibérica. Algunas reflexiones sobre las relaciones mediterráneas". Pyrenae, 28, 99-117.

RAFEL, N. (2003), Les necròpolis tumulàries de tipus baixaragonès: les campanyes de l'Institut d'estudis Catalans al Matarranya, Monografies del MAC, 4, Barcelona.

RALLO, A. (1989): Le donne in Etruria, Roma, 1989.

REINHARD, W. (1997): “Les sépultures aristocratiques de la Sarre au Hallstatt final et à La Tène ancienne", P.Brun y B.Chaume (dirs.): Vix et les éphèmères principautés celtiques. Les Vie et Ve siècles avant J.-C. En Europe centre-occidentale, Actes du Colloque de Châtillon-surSeine (27-29 octobre 1993), 107-124.

ROBINSON, D.M. (1942): Necrolynthia, a study in Greek burial customs and anthropology, Excavations at Olynthus, part XI, BaltimoreLondon-Oxford, Johns Hopkins University studies in Archaeology 32.

ROYO, J.I. (1994): “Estelas y cipos funerarios en la necrópolis tubular de los Castellets de Mequinenza (Zaragoza, España)", V Congreso Internacional de Estelas Funerarias, I, Soria, 117-134.

ROYO, J.I. (1994-1996): "Ritual funerario y cultura material en las necrópolis tumulares de los Castellets de Mequinenza (Zaragoza): una aportación al estudio del bronze final/hierro en el N.E. peninsular", Gala, 3-5, 93-114, Models d'ocupació, transformació $i$ explotació del territori entre el 1600 i el 500 a.c a la Catalunya meridional $i$ zones limítrofes de la Depressió de l'Ebre, Sant Feliu de Codines.

RUTA-SERAFINI, A., BALISTA, C., DeVANNA, L., GAMBACURTA, G. (1992): "La necropoli romana e preromana tra via Tiepolo e via S.Massimo: nota preliminare", $Q A V$, VIII, 15-25.

SALZANI, L. (2001): “Gazzo. Scavi nella necropoli della Colombara”, $Q A V, \mathrm{XVII}, 83$ i ss.

SALZANI, L. (2004): "4.22.b Schinieri in bronzo. Desmontà di Veronella (Verona)", Guerrieri, principi ed eroi fra il Danubio e il Po, dalla preistoria all'alto medioevo, Trento, 586-587.

SANMARTÍ, E. (1982): "Les troballes funeràries d'època ibèrica arcaica de la Granja Soley (Sta.Perpètua de la Mogoda, Vallès Occidental, Barcelona)". Ampurias, 44, Barcelona, 71-103, 1982.
SANMARTÍ, E. (1982b): Les influences méditerranéenes au nord-est de la Catalogne à l'époque archaïque et la reponse indigène, I focei dall'anatolia all'Oceano, PP, CCIV-CCVII, 281298.

SANMARTÍ, E. (1988) : "Una estela de querrer procedent d'Empúries", Fonaments, 7, 111114.

SANMARTÍ, J. (2001): "La formació i desenvolupament de les societats ibèriques a Catalunya", BRSAT, Època V, 23, 101-132.

SANMARTÍ, J. (2007): "El arte de la Iberia Septentrional”, in L.Abad y J.A.Soler (Eds.): Actas del congreso Arte Ibérico en la España Mediterránea (Alicante 24-27 octubre 2005), 239-164.

SCHEID, J. (1985): "Sacrifice et banquet à Rome, Quelques problèmes," MEFRA, 97, 193-206.

SMITH, C. (1996): "Dead Dogs and Rattles. Time, space and ritual sacrifice in iron Age Latium", In, J.B.Wilkins (Ed.): Approaches to the Study of Ritual, Italy and the Ancient Mediterranean, 73-90.

SNODGRASS, A.M. (1982): "Les origines du culte des heros in Grece antique," in G. Gnoli and J.P. Vernant, eds. La mort, les morts, dans les societies anciennes. Cambridge: 107-119.

SNODGRASS, A. (1988): "The Archeology of the Hero," B.D'Agostino (Dir.): Atti del Colloquio Internazionale di Capri: La Parola, L'immagine, La tomba, AION ArchStAnt, X, 19-26.

SOLIER, Y., RANCOULE, G., PASSELAC, M. (1976): La nécropole de "Las Peyros" VIe siècle av.J.-C. a Couffoulens (Aude). RAN, suppl.6, 1976.

SOMMELA, P. (1972): "Heroon di Enea a Lavinium. Recenti scavi a Pratica di Mare », Rend.Pont.A.Pont, XLIV, 47-74.

STEINGRÄBER，S. (1991): "Etruskische Monumentalcippi”, ArchClas 43, 1079-1102.

STEINGRÄBER, S. (1997): “Le culte des morts et les monuments de pierre des nécropoles étrusques“, in F.Gaultier e D.Briquel (éd.): Les plus religieux des hommes. Etat de la recherche sur la religion étrusque, 97-116.

TAFFANEL, O. Et J. (1962): "Deux tombes de cavaliers du 1er Àge du Fer à Mailhac (Aude)", Gallia, XX, 3-62. 
TAGLIAMONTE, G. (2003): "La terribile belleza del guerriero", esn I Piceni e l'Italia medio Adriatica, Atti del XXII Convegno di Studi Etruschi ed Italici (Ascoli Piceno, Teramo, Ancona, 9-13 aprile 2000), 533-553.

THEODOSSIEV, N. (1998): “The dead with golden faces: Dasaretian, pelagonian, mygdonian and boeotian funeral masks", OJA 17.3, 345-367.

TORELLI, M. (1993): "Reges latini della Preistoria: Iconografia, Cerimoniale, Statuti", R.Olmos y J.A.Santos (Eds.): Iconografía Ibérica, Iconografía Itálica: propuestas de interpretación y lectura. Seria Varia UAM, 3, 21-42.

TORELLI, M. (1997): “Limina Averni, Realtà e rappresentazione nella pittura tarquiniese arcaica", in Il rango, il rito e l'immagine. Alle origine della rappesentazione storica romana, Milano, 122-151.

TOSETTI, G. (2006): “La dernière génération héroïque : un parcours historico-religieux et sémio-narratif, d'Hésiode au ps.-Apollodore", Kernos 19, 113-130.

TOVOLI, S. (1989): Il sepolcreto villanoviano Benacci Caprara di Bologna, Cataloghi delle Collezioni del Museo Civico Archeologico di Bologna, Bologna, 1989.

UROZ, H. (2006): El programa iconográfico religioso de la "Tumba del Orfebre" de Cabezo Lucero (Guardamar del Segura, Alicante), Monografías del Museo de Arte Ibérico de El Cigarralejo, 3 .

VALENZA-MELE, N. (1980): La necropoli cumana di VI e V a.C. o la crisi di un'aristocrazia, Nouvelles contributions à l'étude de la société et de la colonisation eubéenes, Cahiers du Centre J.Bérard, VI, 97 i ss.

VALENZE-MELE, N. (1991): "Vita nell'aldilá e corredi funerari: Evoluzione comparate", DHA, 17.2, 149-174, 1991.

VANZETTI, A. (1992): "Le sepolture a incinerazione a più deposizioni nella protostoria dell'Italia nord-Orientale", Rivista di Scienze preistoriche, 44, 11-209.

VERGER, S. (1997): "L'incineration en urne métallique: Un indicateur des contacts aristocratiques transalpins". P.Brun y B.Chaume (dirs.): Vix et les éphèmères principautés celtiques. Les Vie et Ve siècles avant J.-C. En Europe centreoccidentale, Actes du Colloque de Châtillonsur-Seine (27-29 octobre 1993), 223-238.
VERNANT, J.-P. (1973): "Le marriage en Grèce archaique", $P P$, XXVIII, 51-74, 1973.

VILASECA, S. (1953): Coll del Moro, yacimiento posthallstáttico (Serra d'Almors, Tarragona). Estudios Ibéricos I, Instituto de Estudios Ibéricos y Etnología Valenciana. Dipt. Provincial de Valencia. Valencia.

WHITLEY, J. (1988). "Early states and hero-cults: a reappraisal." JHS 108: 1-9.

WHITLEY, J. (1994): “The Monuments That Stood before Marathon: Tomb Cult and Hero Cult in Archaic Attica”, AJA, 98.2, 1994, 213-230.

WHITLEY, J. (2002): “Too many ancestors". Antiquity 76, 119-26.

ZEVI, F. (1989): "Il mito di Enea nella documentazione archeologica: nuove considerazioni", in Atti del XIX Convegno di studi sulla Magna Grecia: L'epos arcaico in Occidente, Taranto, 277 y ss.

ZIFFERERO, A., (2006): "Circoli di pietre, tumuli e culto funerario. La formazione dello spazio consacrato in Etruria settentrionale tra età del Ferro e alto arcaísmo", MEFRA 118.1, 177-213. 